\title{
Carotid Endarterectomy: A Review
}

\author{
J. Max Findlay, B. Elaine Marchak, David M. Pelz, Thomas E. Feasby
}

\begin{abstract}
Background: Since the validation of carotid endarterectomy (CEA) as an effective means of stroke prevention, there has been renewed interest in its best indications and methods, as well as in how it compares to carotid angioplasty and stenting (CAS). This review examines these topics, as well as the investigation of carotid stenosis and the role of auditing and reporting CEAresults. Investigation: Brain imaging with CTor MRI should be obtained in patients considered for CEA, in order to document infarction and rule out mass lesions. Carotid investigation begins with ultrasound and, if results agree with subsequent, good-quality MRAor CTangiography, treatment can be planned and catheter angiography avoided. An equally acceptable approach is to proceed directly from ultrasound to catheter angiography, which is still the gold-standard in carotid artery assessment. Indications: Appropriate patients for CEA are those symptomatic with transient ischemic attacks or nondisabling stroke due to 70-99\% carotid stenosis; the maximum allowable stroke and death rate being 6\%. Uncertain candidates for CEA are those with $50-69 \%$ symptomatic stenosis, and those with asymptomatic stenosis $\geq 60 \%$ but, if selected carefully on the basis of additional risk factors (related to both the carotid plaque and certain patient characteristics), some will benefit from surgery. Asymptomatic patients will only benefit if surgery can be provided with exceptionally low major complication rates (3\% or less). Inappropriate patients are those with less than $50 \%$ symptomatic or $60 \%$ asymptomatic stenosis, and those with unstable medical or neurological conditions. Techniques: Carotid endarterectomy can be performed with either regional or general anaesthesia and, for the latter, there are a number of monitoring techniques available to assess cerebral perfusion during carotid cross-clamping. While monitoring cannot be considered mandatory and no single monitoring technique has emerged as being clearly superior, EEG is most commonly used. "Eversion" endarterectomy is a variation in surgical technique, and there is some evidence that more widely practiced patch closure may reduce the acute risk of operative stroke and the longerterm risk of recurrent stenosis. Carotid angioplasty and stenting: Experience with this endovascular and less invasive procedure grows, and its technology continues to evolve. Some experienced therapists have reported excellent results in case series and a number of randomized trials are now underway comparing CAS to CEA. However, at this time it is premature to incorporate CAS into routine practice replacing CEA. Auditing: It has been shown that auditing of CEA indications and results with regular feed-back to the operating surgeons can significantly improve the performance of this operation. Carotid endarterectomy auditing is recommended on both local and regional levels.
\end{abstract}

RÉSUMÉ: L'endartérectomie carotidienne: une revue. Introduction: Depuis la validation de l'endartérectomie carotidienne (EAC) comme méthode efficace de prévenir l'accident vasculaire cérébral (AVC), il y a un regain d'intérêt pour ses indications et ses techniques ainsi que ses résultats comparés à ceux de l'angioplastie carotidienne avec pose d'une endoprothèse (ACS). Cette revue traite de ces aspects et de l'investigation de la sténose carotidienne ainsi que du rôle de l'audit et de la notification des résultats de l'EAC. Recherche: L'imagerie du cerveau au moyen de la tomodensitométrie ou de la résonance magnétique devrait être faite chez les patients chez qui on envisage de procéder à une EAC afin de documenter un infarctus et d'éliminer la possibilité de lésions solides. L'investigation carotidienne commence par l'échographie et, si les résultats concordent avec l'angiographie par résonance magnétique ou l'angiographie de bonne qualité, le traitement peut être déterminé sans avoir recours à l'angiographie. Il est tout aussi acceptable de passer directement de l'échographie à l'angiographie qui est l'étalon or de l'évaluation carotidienne. Indications: Les patients qui sont de bons candidats à l'EAC sont ceux qui ont des symptômes d'ischémie cérébrale transitoire ou d'AVC non invalidant dû à une sténose de 70 à $99 \%$ de la carotide. Le taux maximal d'AVC et de décès est de 6\%. Les candidats discutables à l'EAC sont ceux qui ont une sténose symptomatique de 50 à $69 \%$ et ceux qui ont une sténose asymptomatique de $60 \%$ ou plus. Si ces patients sont choisis avec prudence selon les autres facteurs de risque qu'ils présentent (qualité de la plaque et certaines caractéristiques du patient), certains patients vont bénéficier de la chirurgie. Les patients asymptomatiques en bénéficieront si la chirurgie peut être effectuée dans des conditions où le taux de complications majeures est exceptionnellement bas, de l'ordre de 3\% ou moins. Les patients inappropriés sont ceux qui ont une sténose symptomatique de $50 \%$ ou asymptomatique de $60 \%$ et ceux qui sont dans un état instable à cause d'une affection médicale ou neurologique. Techniques: L'endartérectomie carotidienne peut être effectuée sous anesthésie régionale ou générale et, dans ce dernier cas, il existe un certain nombre de techniques de surveillance disponibles pour évaluer la perfusion cérébrale pendant le clampage total de la carotide. Bien que la surveillance ne puisse être considérée comme obligatoire, et qu'aucune technique de surveillance ne se soit révélée clairement supérieure aux autres, L'ÉEG est la technique la plus utilisée. L'endartérectomie par éversion est une variante technique. Il existe des données qui démontrent que la technique courante d'endartérectomie avec patch peut diminuer le risque aigu d'AVC opératoire et le risque de récidive de la sténose à long terme. Angioplastie carotidienne et pose d'une endoprothèse: L'expérience acquise dans ce domaine est en croissance et cette technologie moins effractive continue d'évoluer. Des interventionnistes d'expérience ont rapporté d'excellents résultats dans des séries de cas et des études randomisées comparant l'ACS et l'EAC sont en cours. Cependant, il est prématuré de remplacer l'EAC par l'ACS en pratique courante. Audit: Il est démontré que l'audit des indications de l'EAC et de ses résultats, accompagné de rétroaction auprès du chirurgien, peut influencer significativement le succès de cette intervention. L'audit de l'endartérectomie carotidienne est recommandé tant au niveau local que régional.

Can. J. Neurol. Sci. 2004; 31: 22-36

From the Division of Neurosurgery, Department of Surgery (JMF); Department of Anaesthesia (BEM); Division of Neurology, Department of Medicine (TEF), University of Alberta, Edmonton, Alberta; Department of Diagnostic Radiology, University of Western Ontario, London, Ontario (DMP), Canada

Received May 14, 2003. Accepted infinalform September 5, 2003.

Reprint requests to: J. Max Findlay, 2D1.02 WMHSC, 8440 - 112 Street, Edmonton, Alberta, Canada T6G 2B7 
The use of carotid endarterectomy (CEA) reached peak rates in the mid-1980s but, while enthusiasm was high at that time, evidence of CEA efficacy was low. Rates subsequently fell rapidly as doubts about the benefits and appropriateness of CEA grew. ${ }^{1-3}$ Following the release of randomized clinical trial results positive for CEA, rates in Canada and the United States quickly recovered in the $1990 \mathrm{~s},{ }^{4-9}$ with recorded rates between 100 to 400 per 100,000 healthcare beneficiaries in certain US states, ${ }^{6,8}$ and 26 to 83 per 100,000 population among Canada's provinces. ${ }^{9}$ The increased performance of CEAseen in recent years has been accompanied by renewed interest in the most effective investigation of carotid stenosis, the selection and risk stratification of patients for surgery, surgical outcomes and in the various anaesthetic and technical aspects of the operation. Finally, CEAfaces a new challenge, and that is its comparison to endovascular correction of carotid stenosis with carotid angioplasty and stenting (CAS).

\section{Investigation of Carotid Stenosis}

Computed tomography (CT) or magnetic resonance imaging (MRI) of the brain is indicated for most patients being considered for CEA, a possible exception being those presenting with classic amaurosis fugax and no hemispheric symptoms. ${ }^{10}$ Brain imaging is particularly important in patients with persisting sensory, motor or speech deficits in order to rule out hemorrhage and intracranial mass lesions such as subdural hematomas or tumors which can occasionally present with stroke-like symptoms.

Debate surrounds the need for catheter angiography in assessing symptomatic patients for CEA. Although still the goldstandard in precisely quantifying and characterizing carotid artery stenosis, it is an invasive and uncomfortable investigation, with a combined minor and major complication (primarily stroke) rate approaching $1 \% .{ }^{11}$ Carotid ultrasound has only moderate accuracy compared to catheter angiography, ${ }^{12,13}$ as have CT angiography ${ }^{14}$ and conventional magnetic resonance angiography (MRA). ${ }^{15,16}$ The commonest error with ultrasound and standard MRA is overestimation of the degree of stenosis. With that in mind, mild to moderate carotid stenoses (up to 70\%) determined by ultrasound or MRA in asymptomatic patients warrant monitoring but usually no further action. An argument can be made, however, that carotid ultrasound indicating more severe stenosis combined with confirmatory MRAor CTangiography is sufficient to make a decision regarding the need for CEAin many patients. ${ }^{17,18} \mathrm{~A}$ recent review of 40 different studies of imaging and measurement of carotid stenosis found the majority had insufficient methods and standards to inform clinical practice, ${ }^{19}$ emphasizing the difficulty drawing firm conclusions regarding best and safest carotid imaging at the present time.

Currently, carotid artery investigation usually begins with carotid ultrasound. If significant stenosis is detected, one option is to then proceed to a second noninvasive test, either MRA or CT angiography, and if the results are in agreement with ultrasonography, plan treatment and avoid catheter angiography (Figure 1). This approach would be particularly suitable for patients with symptomatic stenosis where both tests indicate $\geq 70 \%$ and CEA is strongly recommended (Figure 2). It is important that both invasive tests are obtained in a timely fashion and that catheter angiography can follow promptly if the results

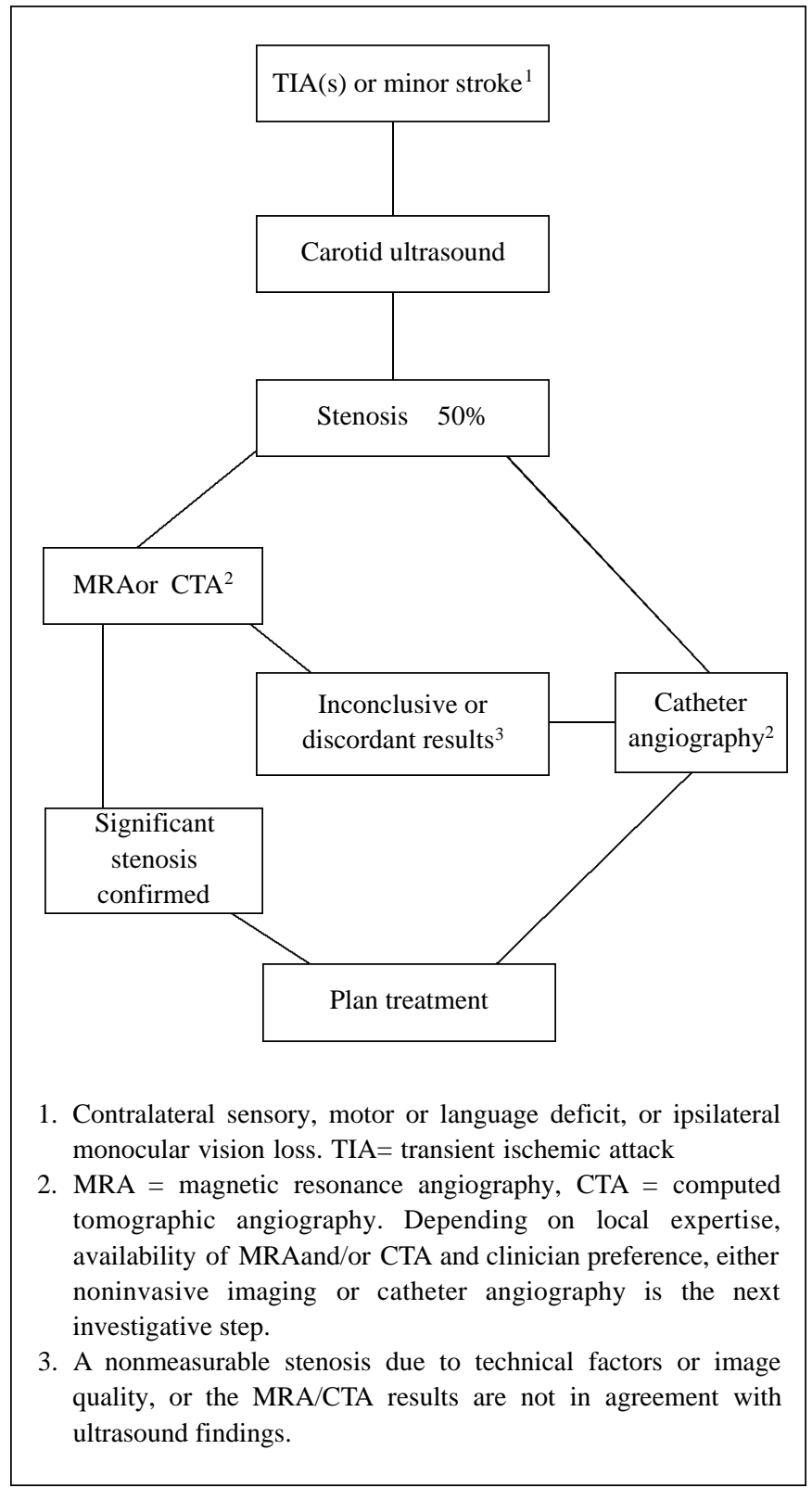

Figure 1: Suggested flow-chart for the investigation of symptomatic carotid stenosis. Testing begins with a carotid duplex ultrasound which, while not accurate in providing a precise degree of stenosis, is usually able to detect potentially significant stenosis, $50 \%$ or greater. The next investigation can be either a noninvasive test, such as magnetic resonance angiography (MRA) or computed tomographic angiography (CTA), or a catheter cerebral angiogram. The choice will depend upon availability of the different imaging modalities as well as physician preference. If either MRA or CTA is chosen, and the results are in agreement with the ultrasound result, treatment can usually be planned, whereas if the results are inconclusive, catheter angiography is usually necessary.

of the noninvasive investigations are inconclusive and the possibility remains that the stenosis is nonsurgical or the artery is occluded. In a recent study of 350 patients being investigated for CEA, agreement between carotid ultrasound and MRA 

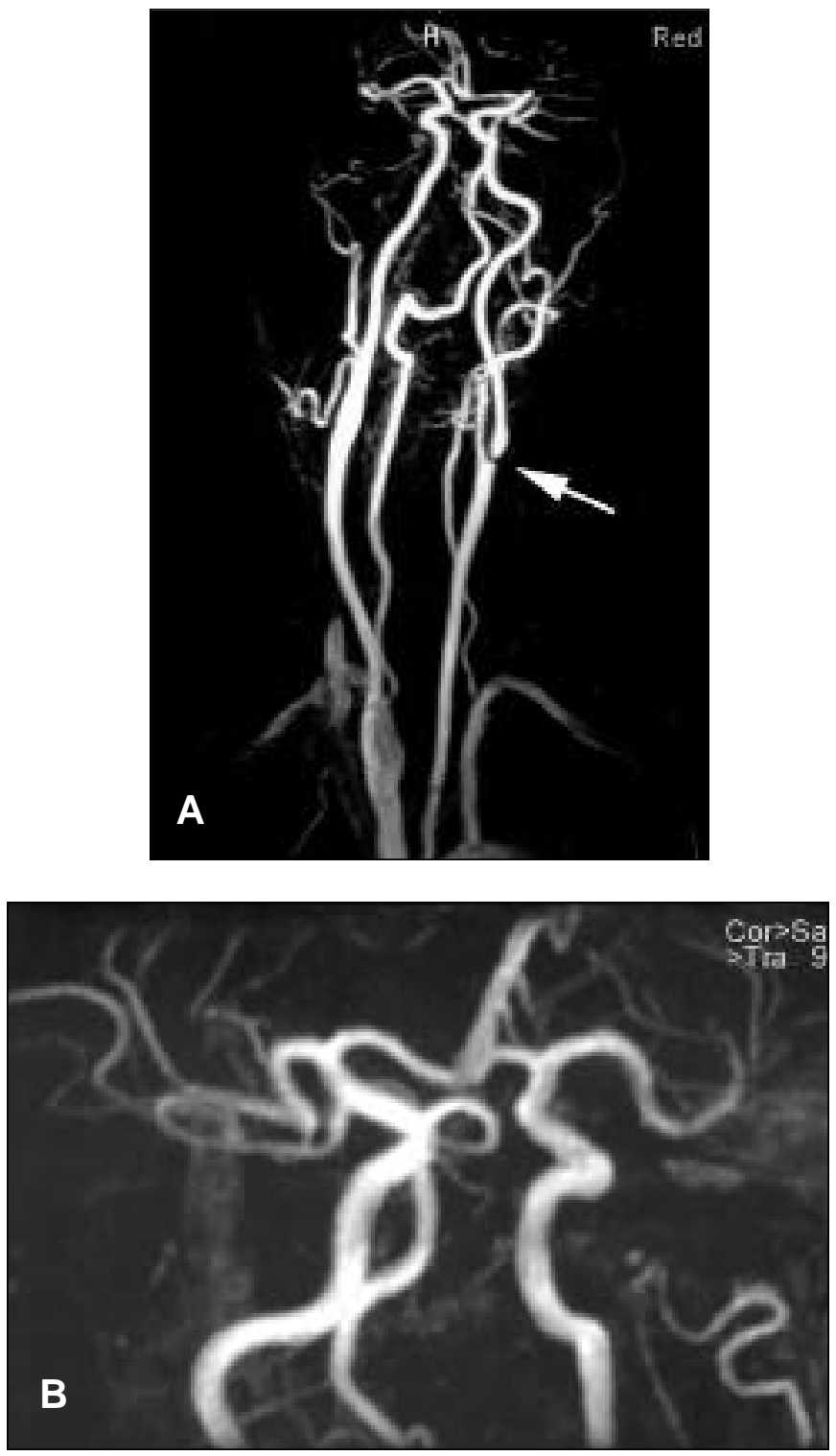

Figure 2: Contrast MRA (A), and time-of-flight MRA (B) can provide adequate assessment of the cervical and cranial arteries, here showing a severe focal stenosis at the origin of the left internal carotid artery (arrow) and normal appearing intracranial vessels. While it is difficult to assign a precise percentage stenosis in this patient presenting after a minor stroke, the result of this study in combination with carotid ultrasonography indicating a 70\% - 99\% left carotid stenosis was sufficient to plan carotid endarterectomy.

$M R A=$ magnetic resonance angiography

results (84\% of 350 patients) gave a sensitivity of $96 \%$ and specificity of $96 \%$ for severe stenosis, compared to reference standard subtraction angiography. ${ }^{20}$

Another approach is to follow carotid ultrasonography positive for stenosis with catheter angiography, accepting the small risk associated with the investigation in exchange for the high degree of accuracy catheter angiography provides for stenosis measurement and treatment selection based on randomized trial data. ${ }^{13,21}$ Other advantages of catheter

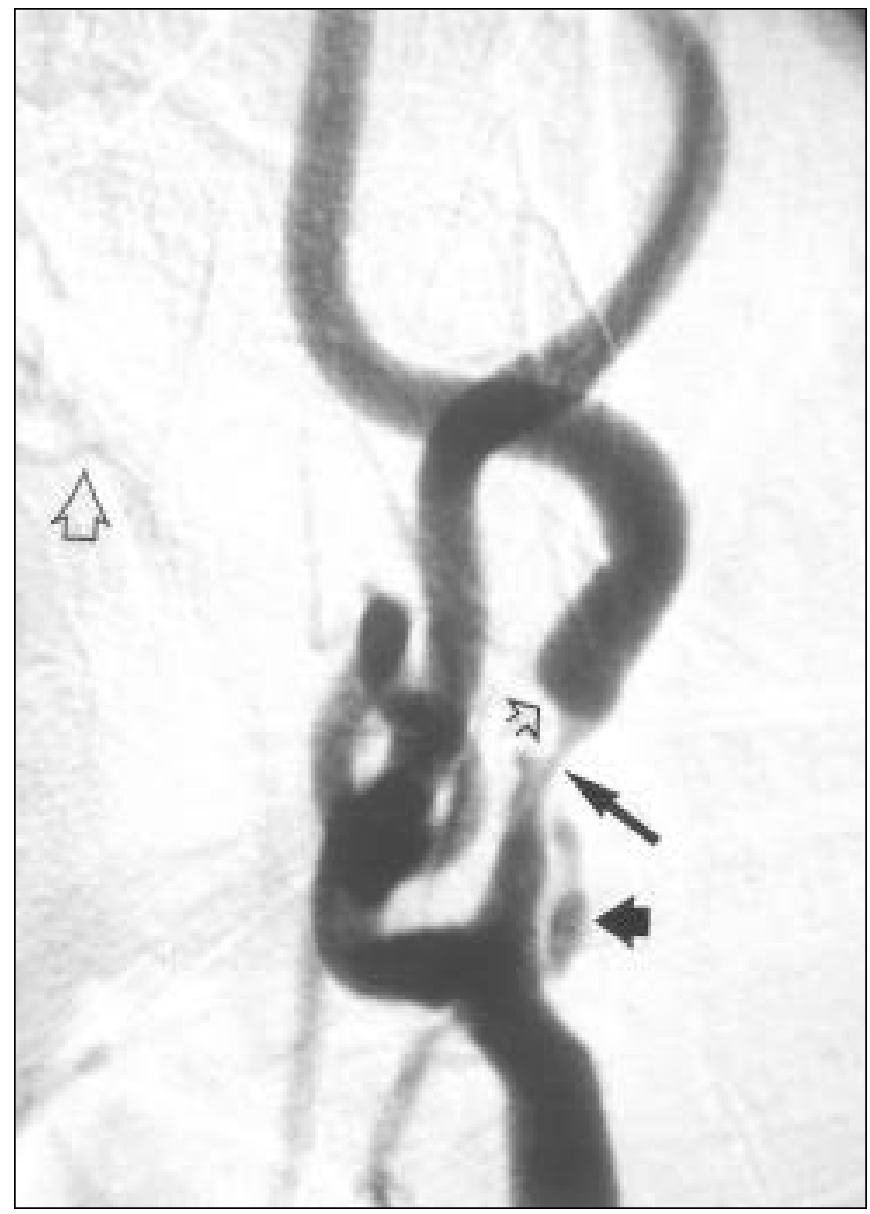

Figure 3: Digital subtraction imaging from catheter angiography is able to provide a precise degree of stenosis (here calculated to be $88 \%$, long arrow), the length of the plaque (small open arrow), the presence of an associated plaque irregularity and ulceration (large arrow) which increases plaque risk, the status of the distal cervical carotid artery and intracranial vessels (only partly shown in this figure), as well as the location of the carotid bifurcation in the neck relative to the cervical vertebrae and mandible, useful in planning the surgical incision (large open arrow beneath the endplate of the second cervical vertebra).

angiography include superior demonstration of plaque morphology including plaque length, ulceration, and any attached intraluminal thrombus, determination of the approximate location of the carotid bifurcation in the neck, detection of intracranial atherosclerosis, and assessment of collateral circulation to the hemisphere (Figure 3). This information is useful in determining the relative need for CEAin patients with moderate (50-69\%) symptomatic stenosis, discussed further in the next section. In the future it is certain that non- or minimally invasive imaging technique, such as contrast - enhanced MRA ${ }^{22-24}$ will be developed and validated to provide the same information as catheter angiography, eliminating the need for diagnostic catheter studies altogether.

The most widely accepted method of measuring carotid stenosis with angiography compares the narrowest diameter of the residual lumen (on the view showing the greatest stenosis) $(\mathrm{N})$ to the luminal diameter of the internal carotid artery beyond 
Table 1: Summary of NASCET results (symptomatic patients) ${ }^{1}$

\begin{tabular}{|c|c|c|c|c|c|c|c|}
\hline \multirow[b]{2}{*}{ Stenosis, $\%^{2}$} & \multirow{2}{*}{$\begin{array}{l}\text { No. of } \\
\text { Patients }\end{array}$} & \multicolumn{2}{|c|}{$\begin{array}{l}\text { Risk of } \\
\text { ipsilateral stroke }\end{array}$} & \multirow{2}{*}{$\begin{array}{l}\text { Absolute } \\
\text { Risk } \\
\text { Reduction, \% }\end{array}$} & \multirow{2}{*}{$\begin{array}{l}\text { Relative } \\
\text { Risk } \\
\text { Reduction, \% }\end{array}$} & \multirow[b]{2}{*}{$\mathrm{NNT}^{3}$} & \multirow{2}{*}{$\begin{array}{l}\text { 30- Day } \\
\text { Perioperative } \\
\text { Stroke and } \\
\text { Death Rate, \% }\end{array}$} \\
\hline & & Medical & Surgical & & & & \\
\hline \multicolumn{8}{|l|}{ 70-99 } \\
\hline 2 years & 659 & 24.5 & 8.6 & 15.9 & 65 & 6 & 5.8 \\
\hline 5 years & 575 & 28.0 & 13.0 & 16.4 & 54 & 6 & 5.8 \\
\hline 5 years & 858 & 22.2 & 15.7 & 6.5 & 29 & 15 & 6.9 \\
\hline \multicolumn{8}{|l|}{$<\mathbf{5 0}$} \\
\hline 2 years & 1368 & 11.7 & 10.2 & $1.5(\mathrm{NS})$ & 13 & 67 & 6.5 \\
\hline 5 years & 1368 & 18.7 & 14.9 & $3.8(\mathrm{NS})$ & 20 & 26 & 6.5 \\
\hline
\end{tabular}

${ }^{1}$ NASCET $=$ North American Symptomatic Carotid Endarterectomy Trial (refs. 26,27,33)

${ }^{2}$ Stenosis according to NASCET measurement method. (ref. 25)

${ }^{3} \mathrm{NNT}=$ the number of patients needed to treat by endarterectomy to prevent one additional ipsilateral stroke in either two or five years (as shown) after the procedure compared with medical therapy alone.

NS = not significant

the bulb where the walls of the artery have become parallel (D), and the percentage of stenosis is calculated as (1-N/D) $\times 100 .^{25}$

\section{INDICATIONS FOR CAROTID ENDARTERECTOMY}

In the past two decades a number of randomized trials have evaluated the benefit and risk of CEA for patients with symptomatic and asymptomatic stenosis of the internal carotid artery. ${ }^{26-33}$ Some of the results from the North American Symptomatic Carotid Endarterectomy Trial (NASCET) are summarized in Table 1. Sufficient time has passed since the publication of these studies to analyze their results and implications and make general recommendations about the application of CEA based on current knowledge. A number of

\section{Table 2: Guidelines for performance of carotid endarterectomy}

\section{Appropriate patients}

- Symptomatic 70-99\% stenosis

Uncertain patients (careful patient selection required)

- Symptomatic 50-69\% stenosis

- Asymptomatic 60-99\% stenosis

\section{Inappropriate patients}

- $<50 \%$ symptomatic stenosis

- $<60 \%$ asymptomatic stenosis

- Unstable medical or neurological status

- Recent large cerebral infarction

- Decreased level of consciousness

- Surgically inaccessible stenosis organizations and experts have published their analyses of the trials, and created guidelines for the use of CEA. ${ }^{34-44}$

Carotid endarterectomy is highly appropriate for patients with symptomatic, severe (70\%-99\%) stenosis causing either transient ischemic attack (TIA) or nondisabling stroke (Table 2). The maximum allowable rate of all strokes or death in this group of patients is $6 \%$. Patients with symptomatic stenosis in the $50 \%$ $69 \%$ range are uncertain candidates for CEA in general, but many will benefit if selected on the basis of additional features indicative of a higher stroke risk when treated with medical therapy alone. These factors, which when present, appear to enhance the benefit of CEA (and which pertain to patients with both moderate and severe stenosis) including male sex, ${ }^{27} \mathrm{a}$ hemisphere as opposed to retinal presentation, ${ }^{45}$ a stroke as opposed to TIA presentation, ${ }^{27}$ a higher degree of stenosis until "near occlusion" (95\% - 99\%) when the risk declines, ${ }^{27,39,46}$ plaque ulceration, ${ }^{47,48}$ contralateral carotid occlusion, ${ }^{49}$ the presence of intraluminal thrombus,${ }^{50}$ the presence of intracranial ("tandem") atherosclerosis, ${ }^{51}$ the absence of collateral pathways to the distal internal carotid artery, ${ }^{52}$ and the presence of leukoaraiosis (white-matter changes) on brain CT scanning. ${ }^{53}$

Asymptomatic patients benefit substantially less from CEA and, for any benefit at all, surgery must be performed with particularly low stroke rates, in the range of 2 or $3 \%$ (at least onehalf the stroke rate for symptomatic patients). Selected results from the two randomized controlled trials examining CEA for asymptomatic stenosis are summarized in Table 3. There may be additional risk factors that increase the risk of an ipsilateral stroke from asymptomatic carotid atherosclerosis. These include male sex, ${ }^{32}$ a higher degree of stenosis, ${ }^{54,55}$ ipsilateral brain infarction on CTor MRI, ${ }^{56}$ plaque ulceration, ${ }^{57-61}$ the presence of an occluded contralateral carotid artery, ${ }^{62}$ a stenosis that progresses over time, ${ }^{63}$ a partly echolucent or heterogenous ("soft") plaque or evidence of intraplaque hemorrhage on ultrasound, ${ }^{63-67}$ and the presence of microemboli detected on 
Table 3: Summary of randomized controlled trials for asymptomatic stenosis

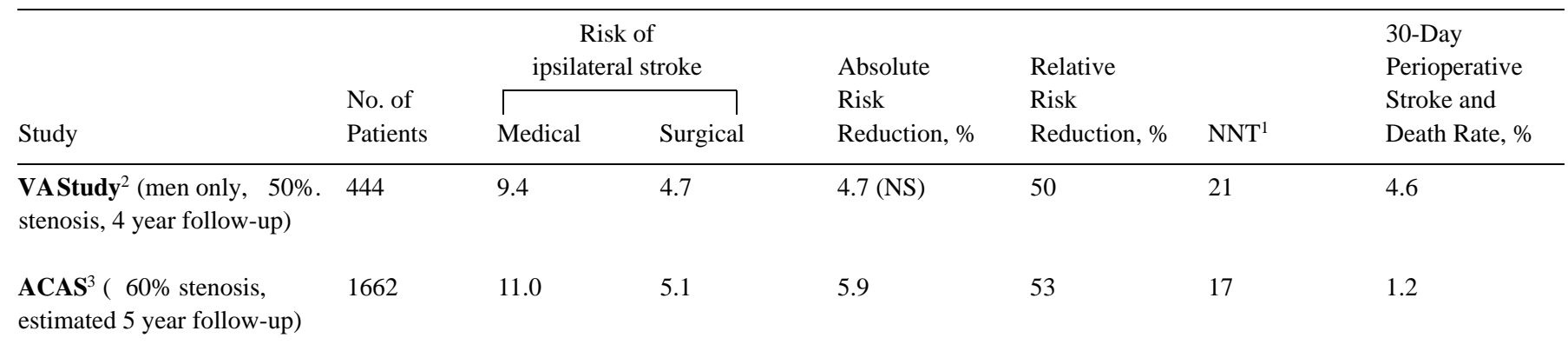

\footnotetext{
${ }^{1} \mathrm{NNT}=$ the number of subjects needed to treat by endarterectomy to prevent one ipsilateral stroke in the number of years after the procedure shown compared with medical therapy alone.

${ }^{2}$ VA Study = Veteran Affairs Cooperative Study (ref. 31)

${ }^{3}$ ACAS = Asymptomatic Carotid Atherosclerosis Study (ref. 32)

NS $=$ Not significant
}

transcranial Doppler. ${ }^{68}$ Asymptomatic stenosis is an uncertain indication for CEA in any circumstance, however, and surgery should only be considered a management option by expert surgeons with very low complication rates in the presence of one or more of these risk factors.

Patients who are inappropriate candidates for CEA are those with less than $50 \%$ symptomatic or less than $60 \%$ asymptomatic stenosis, and those with unstable medical or neurological conditions, such as unstable angina, recent myocardial infarction, uncontrolled congestive heart failure or progressing major stroke.

While there is a strong association between carotid and coronary artery atherosclerosis, ${ }^{69}$ there is limited evidence that the presence of isolated asymptomatic carotid stenosis is an independent risk factor for ipsilateral stroke in patients undergoing coronary bypass surgery. ${ }^{70-73}$ Patients with coronary symptoms and disease which warrant aortocoronary bypass are not often symptomatic from carotid stenosis at the same time, but these patients probably are at higher risk of perioperative stroke when undergoing cardiac surgery, ${ }^{70,74}$ and the carotid stenosis warrants repair for long-term stroke prevention. When this situation arises, options include staged carotid and coronary procedures, ${ }^{73,74}$ combined coronary bypass surgery and CEA, ${ }^{75-}$ 77 and endovascular treatment of either the carotid or coronary arteries prior to surgical repair of the other. ${ }^{78,79}$ The choice is normally determined by the preference and expertise of surgical teams at individual institutions. At the University of Alberta Hospital, the usual choice is a combined procedure, performing the CEA at the same time as saphenous vein harvesting and closing the neck entirely prior to sternotomy.

\section{Timing of Carotid Endarterectomy}

After a minor and nondisabling cerebral infarct due to carotid stenosis, there is no need to wait weeks or months prior to surgery, as was once thought necessary. ${ }^{80}$ Patients with smaller and clinically more minor strokes marked by monoparesis or mild hemiparesis, followed by rapid improvement face no additional risk if operated on early but are afforded earlier protection from recurrent stroke. ${ }^{81,82}$ Large cortical and subcortical strokes accompanied by major progressing deficits have a high surgical risk and should not undergo early CEA. ${ }^{80}$ Patients presenting with TIAs bear a risk for stroke dependent on a number of clinical and plaque-related variables, ${ }^{83}$ but the period of maximum risk and precisely how quickly surgery should be performed has not been clearly defined. There is reasonable evidence that patients presenting with hemispheric symptoms, especially if recurrent and due to severe and/or irregular carotid stenosis, should undergo surgery as soon as possible and at least within several weeks of diagnosis, ${ }^{83,84}$ and perhaps sooner if these symptoms occur in a "crescendo" fashion, consist of prolonged (>10 minutes) hemispheric symptoms, recur despite antithrombotic therapy, or ancillary testing suggests ipsilateral cerebral hemodynamic compromise. ${ }^{84}$

\section{Risk OF CAROTID ENDARTERECTOMY}

The major risks of CEAinclude ischemic stroke, intracerebral hemorrhage, myocardial ischemia and infarction, congestive heart failure and arrhythmias, neck hematoma with airway obstruction, and cranial nerve injuries. Ischemic stroke can be due to post-endarterectomy carotid thrombosis and occlusion, thromboembolism from the endarterectomy site and to intraoperative cross-clamp ischemia ${ }^{85}$ Intracerebral hemorrhage is an unusual complication, due to hemorrhagic conversion of a perioperative infarct, postoperative hyperperfusion following repair of a critical stenosis, related to anticoagulation, or a combination of factors. ${ }^{86}$ Cranial nerve injuries are relatively common, but usually minor and transient. ${ }^{87}$ Neck hematomas can be life-threatening when the airway is compressed. Surgical results of 1415 patients in the NASCETincluded an overall $6.5 \%$ rate of all stroke and deaths at 90 days from CEA, most strokes due to thromboembolism, one-third occurring during surgery and two-thirds postoperative. ${ }^{88}$ Disabling stroke or death occurred in $2 \%$ of patients. Cranial nerve injuries occurred in $8.6 \%$ and neck hematomas in $7.1 \%$, although the majority of these local wound complications were mild.

It is clinically useful to be aware of those features associated with a higher risk of surgery in individual patients and a number of authors have correlated clinical and angiographic variables 
Table 4: Factors which correlate with an unacceptable risk of CEA (contraindications for surgery)*

- Recent large cerebral infarction

- Hemorrhagic infarction

- Progressing stroke

- Alteration in consciousness

- Unstable medical condition: unstable angina, recent myocardial infarction, uncontrolled congestive heart failure, hypertension or diabetes mellitus

*These may be temporary contraindications, and CEAcan be reconsidered once condition(s) have stabilized, controlled or improved

with outcome in order to stratify patient risk for CEA. ${ }^{89-98}$ Consistent predictors of a higher operative stroke and death rate have been hemispheric versus ocular ischemia presentations, female sex, age over 75 years, and occlusion of the opposite carotid artery. Ulceration or irregularity of the carotid plaque was a risk factor in several large series, as was intraluminal thrombus, atherosclerosis in the carotid siphon, peripheral vascular disease, severe hypertension and a history of congestive heart failure. Notably, a number of these features also predict a higher natural history risk of stroke (or risk with medical treatment alone) and, in balance, indicate an even greater benefit from CEA. The presence of one or more of the aforementioned risk factors does not preclude benefit from CEAin many patients with threatened stroke, but does modify the risk of surgery. Contraindications to CEAare shown in Table 4.

Finally, several recent reports support an impression held by many that repeat or "redo" CEAis associated with a significantly higher perioperative complication rate, related to both cranial nerve injury and stroke. ${ }^{99,100}$ Another recent series has refuted this finding. ${ }^{101}$ The advisability of monitoring, the natural history and best management for asymptomatic recurrent carotid stenosis remains quite uncertain. ${ }^{102}$

While there appears to be no clear relationship between CEA outcome and surgical specialty, ${ }^{88,103-105}$ low case volumes per surgeon (especially less than five cases per year) have consistently been associated with poor results. ${ }^{103,105,106}$

\section{Surgicaland Anaesthetic Techniques}

There are many variations practiced in the details of CEA surgical and anaesthetic technique. Principles common to all carotid surgeons include: (1) an exposure of the internal carotid artery to beyond where the atherosclerotic plaque is thought to terminate; (2) a meticulous and complete plaque removal, leaving in particular a smooth "distal end" where the plaque bed meets normal intima; (3) a careful arteriotomy closure (or patchangioplasty) ensuring no stenosis or flow disturbance that might lead to postoperative thrombosis or embolism; and (4) declamping the internal carotid artery only after external carotid and common carotid artery reopening, so that no unseen air or debris trapped at or near the repair site be sent to the cerebral circulation when flow is reestablished (Figure 4). Careful exposure of the bifurcation reduces the risk of cranial nerve injury, absolute hemostasis reduces the risk of neck hematoma,

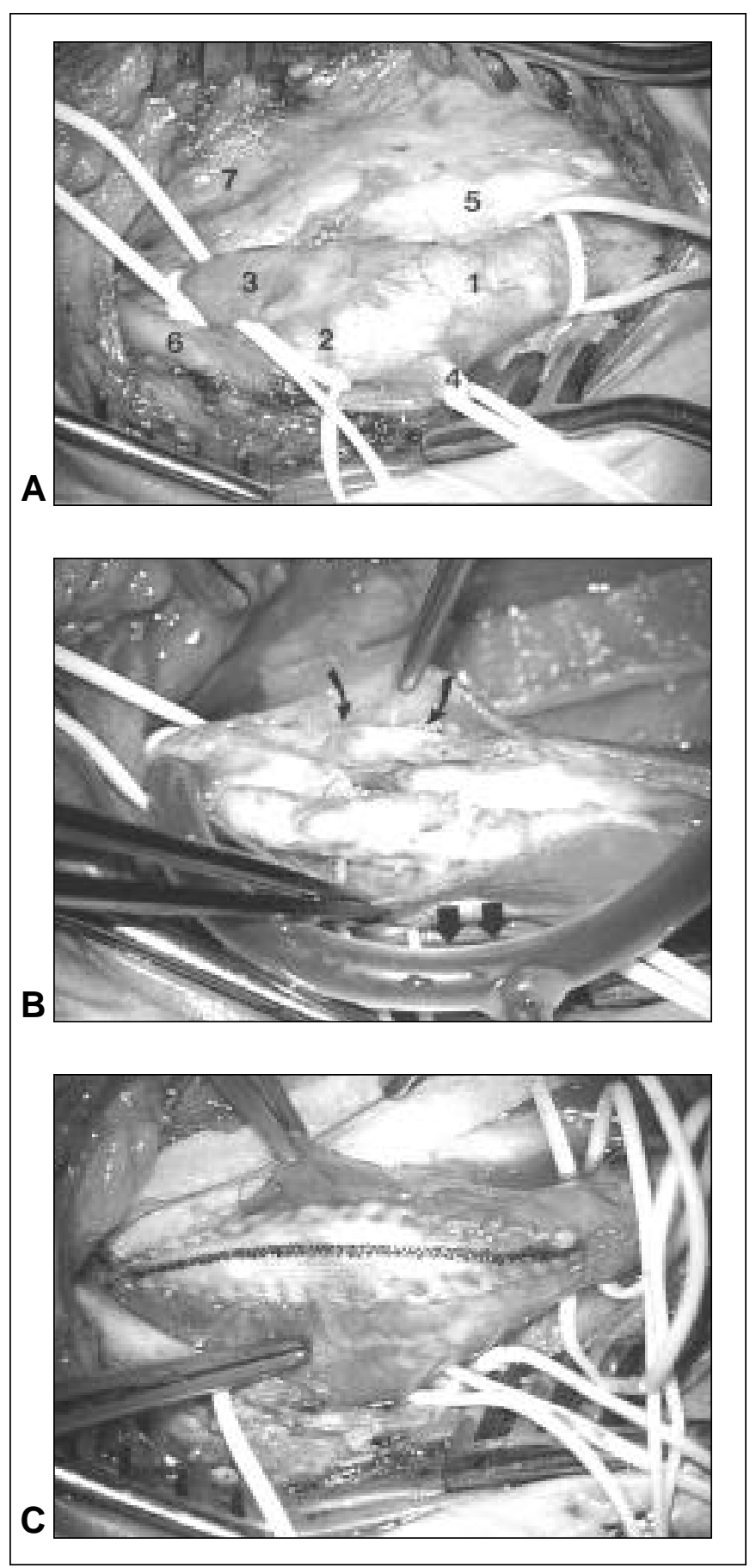

Figure 4: Surgical exposure of the carotid bifurcation (A) showing vessel loops around the common (1), external (2) and internal (3) carotid arteries, as well as the superior thyroidal artery (4), the vagus nerve (5), the hypoglossal nerve (6), and the internal jugular vein (7). The artery and plaque have been opened $(B)$ and a bypass shunt inserted (large arrows). The atherosclerotic plaque, containing a severe and ulcerated stenosis (smaller arrows) is separating easily from the outer, advential vessel wall layer. Following endarterectomy and completion of a patch angioplasty using a woven graft material to augment lumen size, blood flow through the internal carotid artery has been restored $(C)$. 


\section{Table 5: Avoidance of complications during CEA}

\section{Hypoglossal nerve injury:}

The nerve can be applied to an overlying facial vein (especially a higher one) and should be avoided each time a vein overlying the carotid bifurcation is divided. When the nerve must be moved for internal carotid artery exposure, cut the descendens hypoglossi and mobilize, rather than retract. If inadvertently divided, the nerve should be reanastomosed with microsutures.

\section{Vagus nerve injury:}

Leave the nerve adherent to the internal jugular vein and protect with overlying Cottonoid strip.

\section{Facial nerve (or branch) injury:}

Avoid dissection into the parotid gland and replace excessive manual retraction of the apex of the wound (with a right-angle retractor) with fish-hooks.

\section{Accessory nerve injury:}

Avoid excessive posterior mobilization of the proximal sternomastoid muscle.

\section{Intraoperative embolization:}

Avoid excessive mobilization of the carotid bifurcation from its bed during dissection, expel all air from the internal carotid artery by deoccluding the external carotid artery prior to final arteriotomy closure, and declamp the external carotid artery, common carotid artery, and internal carotid artery in that sequence to send any debris from the common carotid artery into the external carotid artery.

\section{Incomplete plaque removal or rough distal end:}

Ensure ample distal internal carotid artery exposure and access before arteriotomy, and use magnification for plaque bed inspection.

\section{Cross-clamp ischemia:}

Aim for 30 minutes or less. Consider shunting if EEG, somatosensory evoked potentials, or transcranial Doppler monitoring suggest distal ischemia, if there is scant reflux of blood down the internal carotid artery temporary declamping, or in the setting of contralateral internal carotid artery occlusion or a hypoplastic anterior precommunicating artery.

\section{Distal subintimal dissection:}

Use tack-down sutures on loose or prominent distal intimal shelves.

\section{Stenosing arteriotomy closure:}

Prevent the arteriotomy from slipping into the crotch of the carotid bifurcation. Use magnification and patch liberally (narrow arteries, long or repeat endarterectomies, and problematic distal ends).

\section{Neck hematoma:}

Maintain absolute hemostasis throughout (bi- and monopolar cautery dissection and/or hemostatic scalpel). Use suture ligatures rather than simple suture ties on facial veins. Pay special attention to patients on ticlopidine or clopidrogrel preoperatively. and selective shunting helps prevent ischemia during carotid clamping. No single surgical tool or maneuver can equal the importance of an orderly, set-wise and organized approach to the operative procedure and its variations required under special circumstances. Surgical steps useful in complication avoidance during CEAare listed in Table 5.

\section{Magnification}

Although the modern surgical microscope is felt by some to be an adjunct to $\mathrm{CEA}^{107,108}$ the same is true of any type or degree of magnification used during the procedure. Certainly the microscope, with its variable magnification and superior illumination enhances distal carotid visualization, plaque removal and arteriotomy repair, but it is primarily an instrument available to and used by neurosurgeons. Many surgeons employ operating loupes and headlamps.

\section{Eversion Endarterectomy}

This is a technique where the internal carotid artery (ICA) is transected at its origin from the common carotid artery bifurcation, the inner atheroma is grasped and the outer adventitial layer is peeled and everted over the ICAplaque to its distal end and detached. The internal carotid artery is then reanastomosed to the bulb with a running suture. It is inappropriate for patients with significant common carotid artery atheroma and stenosis, and use of a shunt is more difficult than with conventional CEA, but proponents consider the procedure faster, and the risk of recurrent stenosis less. ${ }^{109-112}$ It has been compared to standard CEA in a randomized trial in Europe, without any clear differences apparent in that study ${ }^{113}$ or a review of the literature. ${ }^{114}$

\section{Patch Closure}

Possible benefits from the augmented lumen diameter provided by patch angioplasty include a reduced acute thrombosis risk as well as a lower incidence of longer term restenosis. Patch materials commonly used include autologous saphenous vein, various synthetic materials such as polytetrafluorethylene (PFTE; Gore-Tex), the polyester fabric Dacron which is also provided collagen-impregnated, and bovine pericardium. ${ }^{115}$ Vein grafts provide an endothelialized luminal surface and the suture lines are especially hemostatic, but they require harvesting and a second wound, and there have been rare reports of postoperative rupture and aneurysm formation associated with vein patches. ${ }^{116}$

The use of patch closure varies among surgeons. In NASCET a simple closure was used in $79 \%$ of 1,415 patients, a fabric patch in $10 \%$ and a vein patch in $10 \% .{ }^{88}$ Patch closure was more commonly performed by vascular- rather than neurosurgeons, but did not correlate with perioperative stroke risk. Patch closure was used in $28 \%$ of 1,729 operations in the European Carotid Surgery Trial, and again there was no association with its use and the risk of stroke or death. ${ }^{96}$

In a small study of 74 patients that underwent bilateral CEAs, patch closure on one side (either PFTE or saphenous vein) and primary closure on the other (staged operations in a random sequence), it was found that patching was associated with a lower operative stroke (4\% for primary closure versus $0 \%$ for patching), lower incidence of ultrasound-detected restenosis (22\% versus $1 \%$ ) and better cumulative patency rate, differences 
that were all statistically significant. ${ }^{117}$ These results concur with a prior randomized trial by the same group comparing the two techniques in different patients, ${ }^{118}$ and with a systematic analysis of the literature on the subject. ${ }^{119}$ Outcome differences between vein and synthetic patches have not been detected. ${ }^{120,121}$

There appears to be benefit in a liberal or possibly even routine use of patches, but the choice of patch material seems less important at this time. Although their selection is often arbitrary, patients who might be the most logical candidates for patch closure are those with either small internal carotid arteries or long plaques and arteriotomies (i.e. $<5 \mathrm{~mm}$ and $>20 \mathrm{~mm}$, respectively), patients undergoing repeat endarterectomy, and those patients who are considered young for CEA (i.e. age less than 60 years). Given the number of variables involved, it is understandable that some surgeons have adopted a "patch all" policy, and immediately available synthetic grafts have only simplified this decision.

\section{Carotid Occlusion}

A number of studies have proven the feasibility of reopening acutely occluded ICAs, successful cases usually being those presenting with a TIA or minor stroke (and therefore adequate collateral blood flow to prevent a major hemispheric infarct with the loss of the ICA) who are found on angiography to have retrograde reflux filling from collateral sources to the level of the petrous or distal cervical ICA. ${ }^{122-125}$ To be successful, deocclusion must be undertaken early, preferably within several days. Whether or not the benefit of reopening a carotid outweighs the risk of the patient who has tolerated its loss is open to question. Advocates point to studies indicating a roughly $5 \%$ annual stroke risk distal to an occluded ICA. ${ }^{126}$

The specifics of carotid thrombectomy require description. Following exposure of the carotid bifurcation, passage of vessel loops around the common, external and internal carotid arteries, and systemic heparinization, only the common and external carotid arteries are occluded. An arteriotomy is made, exposing a column of thrombus distal to the stenosis. In the best of circumstances, suction and mechanical traction on the thrombus with forceps will retrieve the entire column of clot from the internal carotid artery, propelled and followed by retrograde bleeding. In many patients, however, a no. 2 Fogarty catheter needs to be passed up the internal carotid artery $10-12 \mathrm{~cm}$ (or until resistance is felt, whereupon the catheter should be withdrawn $1 \mathrm{~cm}$ ), its balloon inflated, and the catheter withdrawn, retrieving thrombus and hopefully followed by backbleeding. If, after several attempts, little or no back-bleeding is established, the ICA should be ligated. If retrograde bleeding is established, a regular CEA should be carried out and flow restored up the internal carotid artery. In these circumstances, an intraoperative completion angiogram should be considered. A danger of this maneuver is the creation of a carotid-cavernous fistula, so care must be taken not to advance the catheter too far, or against resistance.

\section{Intraoperative Carotid Imaging}

Some surgeons consider intraoperative vascular imaging either with ultrasound, angioscopy or angiography useful in ruling out technical errors in the repair such as an intimal flap, although the usefulness of this in reducing operative stroke risk has not been shown. ${ }^{127-130}$

\section{Anaesthesia and Monitoring}

Anaesthetic and perioperative risk in patients presenting for CEA is significantly increased by the frequently accompanying co-morbidities of ischemic heart disease, peripheral vascular disease, hypertension, obesity, diabetes and respiratory disease.

General anaesthesia remains the predominant anaesthetic technique for CEA. ${ }^{131-134}$ The goals in the management of patients undergoing general anaesthesia for CEAare to maintain cerebral perfusion pressure without unduly increasing myocardial oxygen demands and to ensure rapid emergence and return to an alert state in order to facilitate prompt postoperative neurological assessment. The advantages of general anaesthesia include guaranteed immobility, optimum patient positioning, lack of pressure to complete a procedure in a patient who is restless or uncomfortable and excellent control of oxygenation and ventilation. Most general anaesthetics reduce the cerebral metabolic rate of oxygen and may improve cerebral tolerance to ischemia. The major disadvantage of general anaesthesia is the loss of ability to assess the adequacy of cerebral perfusion, particularly at the time of carotid clamping. The availability of a monitor which accurately detects significantly impaired cerebral perfusion could direct therapeutic interventions such as deliberate hypertension, use of potentially neuroprotective drugs and carotid shunting.

Unfortunately, a highly sensitive and specific monitor of cerebral perfusion for use in the intraoperative setting does not exist. No monitoring modality has emerged as clearly superior and consequently there is wide variation in clinical practice. The monitoring modalities which have been studied in CEA include stump pressure, EEG, somatosensory evoked potentials (SSEP), transcranial Doppler (TCD), and near infrared spectroscopy or cerebral oximetry.

Measurement of stump pressure was one of the earliest techniques used in an attempt to measure the adequacy of collateral flow after carotid clamping. The threshold pressure considered to be significant varies widely among studies. Overall predictive value for new neurological deficits is low. ${ }^{135}$

Electroencephalography has a long history of use in CEA ${ }^{136}$ and is probably the monitor most commonly currently used. An EEG primarily reflects changes in cortical activity and may not reflect ischemia in subcortical structures. Cortical activity is monitored only in the area beneath the overlying electrode and therefore the ability to detect ischemia is affected by the number of leads and their position. The EEG interpretation will be complicated by presence of anaesthetic agents, ${ }^{137}$ changes in anaesthetic depth and the presence of pre-existing stroke.

Unlike EEG, SSEPs are sensitive to both cortical and subcortical ischemia. Advantages of SSEP monitoring include less sensitivity to anaesthetic effect than EEG and some utility in the presence of previous stroke. ${ }^{138}$ Reported sensitivities and specificities for SSEPs predicting postoperative neurologic deficits are variable.

Changes in middle cerebral artery flow velocity as measured by TCD have been used as markers for ischemia during CEA. ${ }^{139}$ Unlike all of the other CEA monitoring modalities, which are primarily focused on detecting hemodynamic events resulting in cerebral ischemia, TCD can be used to detect embolic events as they occur. Detection of emboli allows for possible alteration of surgical technique. Significant numbers of emboli on closure 
may indicate impending luminal thrombosis. ${ }^{140}$ Transcranial Doppler may also be useful in predicting postoperative hyperperfusion syndrome. ${ }^{141}$

With cerebral oximetry or near infrared spectroscopy, oxygen saturation of hemoglobin contained in arteries, veins and capillaries is measured by a sensor placed in direct contact with scalp. Sensor placement, regional variation in flow and contamination by extracranial blood flow may all introduce errors. Thresholds for identification of ischemia have been difficult to define ${ }^{142}$ with variable predictive values for postoperative deficit. ${ }^{143}$

There has been an increasing interest in the use of regional anaesthesia for CEA. A combination of deep and superficial cervical plexus block appears to be the most common technique. Superficial block alone may be as effective as combined block with potentially fewer complications. ${ }^{144}$ An additional mandibular nerve block may be helpful in alleviating jaw pain in patients with high carotid bifurcations. ${ }^{145}$ The major advantage to regional anaesthesia is the ability to continuously monitor neurologic function which obviates the need for additional cerebral monitoring and allows for highly selective shunt placement, and some believe regional anaesthesia may be associated with a smaller incidence of cardiopulmonary disturbances and a shorter hospital stay. The disadvantages are difficult airway access in emergent circumstances, frequent intraoperative hypertension and the requirement for a cooperative patient.

Debate continues as to the influence of anaesthetic technique upon postoperative morbidity and mortality. There is no clear evidence that postoperative stroke rates are influenced by anaesthetic technique. A large prospective randomized trial is required to address this issue definitively. ${ }^{146}$ The authors' (J.M. Findlay and B.E. Marchak) preference is general anaesthesia in order to position the patient for use of the operating diploscope, in combination with intraoperative EEG monitoring for crossclamp ischemia and selective shunt use.

\section{Perioperative Management}

All patients should receive antiplatelets before CEA, usually aspirin at a dosage of at least $81 \mathrm{mg}$ per day, to reduce the risk of postoperative stroke. ${ }^{147}$ Intravenous heparin can be continued right until the moment of surgery, oral anticoagulation should be completely reversed, and while patients receiving clopidogrel can undergo CEA, they require special attention with respect to arteriotomy and wound hemostasis (ie. complete reversal of intraoperatively administered heparin).

The routine postoperative care of CEA patients has changed significantly in recent years. ${ }^{148,149}$ Because of a high incidence of coexistent cardiac disease and hypertension, and a greater amount of hemodynamic instability than most surgical patients exhibit, a step-down or close-observation unit for 12 hours or overnight post-CEA(with an indwelling arterial line and cardiac telemetry) is appropriate. Patients can be safely discharged after a total of two to three days in hospital if there have been no complications.

Bradycardia and hypotension are common in the first 12 hours following CEA, and are usually responsive to intravenous atropine. Care must be taken not to induce hypervolemia with repeated fluid boluses if the patient has a history of congestive heart failure, and a vasopressor agent is rarely required. Significant hypertension usually responds to intravenous labetolol.

\section{Neck Hematomas}

Neck hematomas complicating CEA can be life-threatening. Among the 1,415 surgical patients in NASCET, neck hematomas were recorded in 101 (7\%), one-half of these required a return to the operating room or delayed discharge, and two patients died from airway obstruction. ${ }^{88}$ An arteriotomy or patch dehiscence (carotid "blow-out") is fortunately very rare, since it can be rapidly fatal. Patients should be constantly checked in the first few hours following CEA, and while mild hematomas not causing pain or difficulty breathing may stabilize with pressure, hematomas causing any degree of stridor or distress are most safely treated by surgical evacuation of the clots.

In more extreme circumstances of frank hypoxia with imminent respiratory arrest, emergency intubation should be performed by a skilled anaesthetist, in the operating room if at all possible. Intubation is difficult, and urgent surgery must follow. If the hematoma causes enough airway distortion to prevent visualization of the vocal cords, then the wound should be immediately opened to decompress the airway and an attempt at intubation repeated. Tracheostomy under these circumstances is a last resort. It is sometimes difficult to locate the precise source of bleeding in these patients once an airway is secured and the wound is opened for thorough exploration. Following surgical evacuation of a neck hematoma patients should remain intubated at least overnight and until swelling begins to subside and an air leak is detected around the endotracheal tube when the cuff is deflated.

\section{Postoperative Stroke}

The majority of strokes occur during or within 12 hours of surgery, and ICA thrombosis or thromboembolism account for the majority. ${ }^{150}$ Hemorrhage is a rare cause of postoperative stroke, often related to repair of a critical stenosis in the presence of a distal infarct in a hypertensive patient. ${ }^{86}$ In NASCET's 1,415 surgical patients there were only two postoperative intracerebral hemorrhages. ${ }^{88}$

In the setting of an acute postoperative stroke causing hemiparesis or hemiplegia, most authorities have recommended either urgent surgical re-exploration or cerebral angiography with the goal of reopening occluded vessels and correcting flaws in the arterial repair. However, there is some question as to the efficacy of these approaches in reversing stroke. The surgical results of NASCET include 10 patients who underwent emergency reoperation for major hemispheric strokes, eight of whom had occluded arteries which were reopened, but none benefited. ${ }^{88}$ Others have reported more favorable results from an aggressive surgical approach to acute postoperative stroke. ${ }^{151} \mathrm{~A}$ recent review of 700 consecutive CEA procedures examined in 13 patients who experienced major hemispheric deficits (hemiplegia with or without aphasia, forced eye deviation, and decreased consciousness) that prompted either immediate surgical re-exploration or cerebral angiography with reoperation on the basis of angiogram results. ${ }^{85}$ Approximately one-half had an underlying, correctable lesion (endarterectomy site occlusion or stenosis), and these patients typically had strokes that occurred after the patient awoke from surgery. Approximately 
Table 6: Management of postendarterectomy neurological deficits

\section{Hemispheric deficits (hemiplegia, forced eye deviation)}

- Immediate carotid angiography or re-exploration to detect and reverse acute carotid occlusion.

\section{Focal deficits}

- In setting of pre-existing neurodeficit (prior stroke), temporize for 30 minutes because postoperative exacerbation of deficit is common, and gradual movement will be noted.

- If no preoperative deficit was present, postoperative deficit may indicate cerebral angiography to detect flaws in the arterial repair and possibly intra-arterial thrombolysis of distal thromboemboli.

- Perform CT scanning if angiography negative for thromboembolism (to rule out intracranial hemorrhage)

one-half of these patients improved as a result of immediate reopening, although new infarcts were seen in almost all on CT scanning.

The options for an aggressive approach include immediate carotid imaging with ultrasound or contrast angiography, surgical re-exploration of the operative site, or perhaps a combination of the two if intraoperative cerebral angiography is available. If available, prompt cerebral angiography best directs further management, which might include endovascular management with thrombolysis or stents. ${ }^{152-155}$ Computed tomography of the brain is less profitable in the first several hours following CEA, given the rarity of acute intracerebral hemorrhage after CEA. The course of action chosen, usually on the basis of the suspected cause of stroke, timing of its onset, and the speed with which either angiography or surgery can be performed, is aimed at detecting and correcting carotid occlusion or significant residual stenosis (Table 6). As with all types of acute and potentially reversible ischemic stroke, speed is of the essence. On occasion, this can result in an important, early neurological improvement.

\section{Carotid Angioplasty and Stenting}

The popularity of CAS for the treatment of carotid stenosis continues to grow (Figure 5). There is good evidence that in experienced hands CAS can be a safe and effective alternative to CEA in selected patients. ${ }^{156,157}$ In the largest single center CAS case series reported to date, the major and minor stroke rates were $1 \%$ and $4.8 \%$, respectively, and the overall stroke and death rate at 30 days was $7.4 \% .{ }^{18} \mathrm{~A}$ world-wide survey of CAS procedures done in $2000^{158}$ and recently updated ${ }^{159}$ indicates a major stroke rate at 30 days of $1.2 \%$, and a minor stroke rate of $2.1 \%$ in over 11,000 treated vessels. The overall stroke and death rate in that survey was $4.8 \%$, and the restenosis rate at 36 months was only $2.4 \%$. The technology of CAS continues to evolve, and a variety of neuroprotective devices to catch emboli during the procedure are now commercially available. ${ }^{160,161}$ Others are being tested in a number of different registries. Early reports

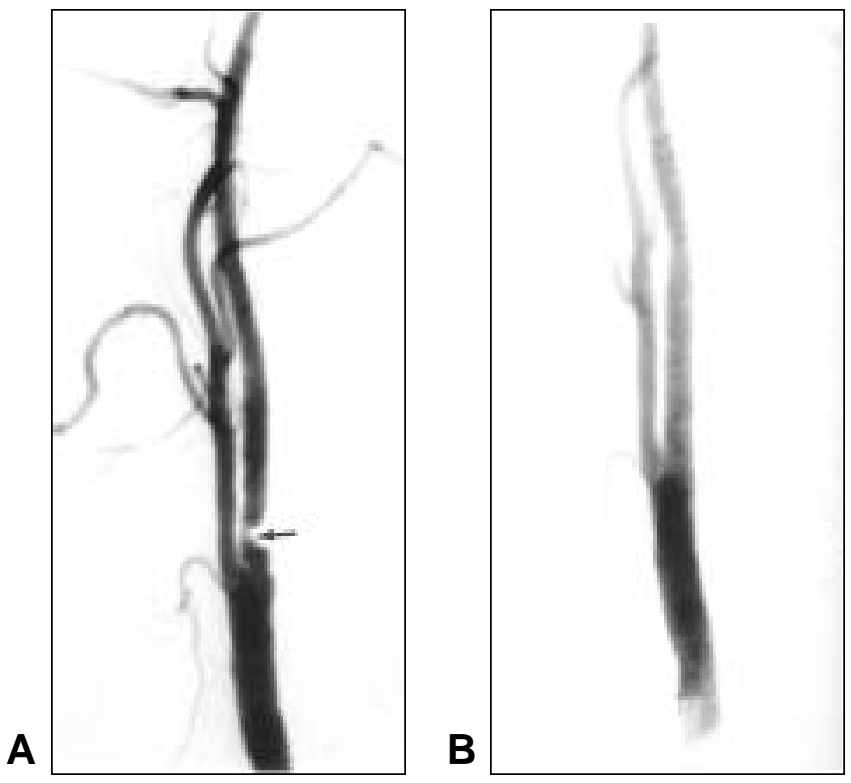

Figure 5: A focal, severe stenosis of the internal carotid artery (A) is completely eliminated following angioplasty and stenting (B). The patient, whose medical condition contraindicated surgery, suffered no complications from the procedure.

indicate that these devices can help lower the neurological complication rates to as low as $1.3 \% .{ }^{160}$ Drug-eluting and bioactive stents designed to reduce the risk of restenosis are presently used in coronary arteries, and will likely soon find neurovascular applications. Carotid angioplasty and stenting can be performed as an outpatient procedure on ambulatory patients $^{162}$ and CAS is possible in patients with significant medical co-morbidities associated with higher surgical risks. ${ }^{163,164}$

However, there have been concerns expressed about the quality of evidence supporting widespread adoption of CAS as an alternative to CEA at this time. ${ }^{165-167}$ These include the large number of single-center series reported thus far, the mixture of symptomatic and asymptomatic patients in many of those series, and the quality and consistency of neurological follow-up. The few direct comparison studies between CAS and CEA, including the Carotid and Vertebral Artery Transluminal Angioplasty Study have shown CAS outcomes that are either the same or worse than CEA. ${ }^{168,169}$ As already discussed, CEA is of more marginal clinical benefit to patients with moderate symptomatic and asymptomatic stenosis, yet patients from these groups have made up a large percentage of many CAS reports. Symptomatic patients are at a higher risk of stroke from CEA than asymptomatic patients, ${ }^{97}$ and if the same applies to CAS, this may have biased the complication rates for CAS reported to date.

Although CAS has been proposed as less costly than CEA, this has also been questioned. Two recent reports have shown lower overall costs associated with CEA. ${ }^{170,171}$ Proponents of regional anaesthesia for CEA have also challenged the notion that patients with medical risk-factors should preferentially undergo CAS. ${ }^{172}$ 
Carotid angioplasty and stenting has been performed for over 10 years, and the balance of evidence indicates that experienced interventionalists can achieve good results with this procedure, a situation similar to the status of CEA prior to its validation in randomized trials comparing surgery to medical therapy alone. There are persuasive arguments for the continued use of CAS. ${ }^{173}$ Observational data can never substitute randomized controlled trials. ${ }^{165,167}$ There are at least 12 such trials comparing CAS to CEA now underway world-wide. ${ }^{159}$ The largest is the Carotid Revascularization Endarterectomy versus Stent Trial (CREST), which after a lengthy initiation ${ }^{174,175}$ is now randomizing patients. In addition to assessing the overall clinical efficacy of CAS compared to CEA, this study will examine differential efficacy between men and women, pre- and postprocedure morbidity, restenosis, differences in quality of life and costeffectiveness, and subgroups of patients at differential risk. CREST plans to randomize 2,200 patients with symptomatic extracranial internal carotid stenosis measured to be $50-99 \%$ by angiography over three years, and it has been predicted to take five years to complete the study. As of December 2002, 257 patients from 60 North American sites had been randomized and the rates of neurological complications in the CAS group were $3.6 \%$ in asymptomatic patients and $6.6 \%$ in symptomatic patients. ${ }^{159}$

Until further information is obtained from studies such as CREST, CEAremains the only validated procedure that has been clearly shown to reduce the risk of stroke. Current evidence does not support the incorporation of CAS into routine clinical practice at present. Special circumstances may warrant its current use, such as radiation-induced carotid stenosis, high cervical and surgically inaccessible stenosis, and symptomatic stenosis when there exists a significant medical contraindication to surgery, such as recent myocardial infarction, unstable angina, or uncontrolled congestive heart failure.

\section{CEA "EfFectiveness" ANd CEA AUditing}

"Effectiveness" of a medical intervention is the equivalent of efficacy, but measured in the "real world" of clinical practice as opposed to a clinical trial. ${ }^{176}$ While efficacy studies (i.e. randomized controlled trials) can tell us if a procedure can work, effectiveness studies tell us it does work in routine clinical practice.

To achieve maximum effectiveness from CEA, which is the greatest number of strokes prevented in the clinical application of this procedure, two conditions must be met. The first is a reduction of perioperative morbidity and deaths to a minimum. This maximizes the absolute risk reduction (ARR) for stroke, leaving it limited only by the risk of stroke if the stenosis was treated medically. This then leads to the second condition, which is maximizing the appropriateness of patient selection for CEA by choosing those patients at greatest risk of stroke and with the most to gain by CEA. These patients have the highest baseline risk of stroke treated medically, the largest ARR with surgery and the smallest "number needed to treat" (calculated as the inverse of the ARR) to prevent a single stroke over a given number of years. The most effective use of CEA would therefore be in patients at highest risk of stroke without surgery when the operation is carried out with the lowest complication rates.

Although methodological shortcomings are unavoidable in retrospective reviews, a number of recent regional and state-wide surveys have reported acceptable CEA stroke or death complication rates for symptomatic patients, ranging between 3 to $7.5 \% .^{8,85,95,104,177}$ Patient selection for CEA has been more variable, as have the criteria for "appropriate" indications. Particularly variable and contentious is designation of asymptomatic patients as "uncertain" or "appropriate". ${ }^{178-182}$ There have also been marked geographical variations in the rate of CEA between countries and regions within countries, most likely reflecting regional clinical practice supply of services. ${ }^{8,9,183,184}$

Carotid endarterectomy is well-suited for examination of its outcomes, complications and appropriateness. Indications for CEA have become quite well-defined, and the major events which complicate CEAare readily detected when hospital records are reviewed and patients contacted for follow up. Aregular CEA auditing process implemented in Edmonton providing direct feedback of surgical indications and operative results to operating surgeons has been found to result in significant improvements in the "effectiveness" of CEA; both surgical indications and results continued to improve over time. ${ }^{185}$

\section{ACKNOWLEDGEMENT}

The authors thank Ms. Laurie Arneson for assistance in the preparation of this paper.

\section{REFERENCES}

1. Winslow CM, Solomon DH, Chassin MR, et al. The appropriateness of carotid endarterectomy. N Engl J Med 1988;318:721-727.

2. Barnett HJ, Plum F, Walton JN. Carotid endarterectomy: an expression of concern. Stroke 1984;15:941-943.

3. Warlow C. Carotid endarterectomy: does it work? Stroke 1984; $15: 1068-1076$.

4. Huber TS, Durance PW, Kazmers A, Jacobs LA. Effect of the Asymptomatic Carotid Atherosclerosis Study on carotid endarterectomy in Veterans Affairs Medical Centers. Arch Surg 1977;132:1134-1139.

5. Hsia DC, Moscoe LM, Krushat WM. Epidemiology of carotid endarterectomy among medicare beneficiaries 1985-1996 update. Stroke 1998;29:346-350.

6. Tu JV, Hannan EL, Anderson GM, et al. The fall and rise of carotid endarterectomy in the United States and Canada. N Engl J Med 1998;339:1441-1447.

7. Morasch MD. Carotid endarterectomy: characterization of recent increases in procedure rates. J Vasc Surg 2000;31:901-909.

8. Kresowik TF, Braztler D, Karp HR, et al. Multistate utilization, processes, and outcomes of carotid endarterectomy. J Vasc Surg 2001;33:227-235

9. Feasby TE, Quan H, Ghali WA. Geographic variation in the rate of carotid endarterectomy in Canada. Stroke 2001;32:2417-2422.

10. Culebras A, Kase CS, Masdeu JC, et al. Practice guidelines for the use of imaging in transient ischemic attacks and acute stroke. A report of the stroke council, American Heart Association. Stroke 1997;28:1480-1497.

11. Hankey GJ, Warlow CP, Molyneus AJ. Complications of cerebral angiography for patients with mild carotid territory ischaemia being considered for carotid endarterectomy. J Neurol Neurosurg Psychiatry 1990;53:542-548.

12. Eliasziw M, Rankin RN, Fox AJ, Haynes RB, Barnett HJ for the North American Symptomatic Carotid Endarterectomy Trial (NASCET Group). Accuracy and prognostic consequences of ultrasonography in identifying severe carotid artery stenosis. Stroke 1995;26:1747-1752.

13. Qureshi AI, Suri FK, Ali Z, et al. Role of conventional angiography in 
evaluation of patients with carotid artery stenosis demonstrated by Doppler ultrasound in general practice. Stroke 2001;32:2287-2291.

14. Anderson GB, Ashforth R, Steinke DE, Ferdinandy R, Findlay JM. $\mathrm{CT}$ angiography for the detection of characterization of carotid bifurcation disease. Stroke 2000;31:2168-2174.

15. Wardlaw JM, Lewis SC, Humphrey P, et al. How does the degree of carotid stenosis affect the accuracy and interobserver variability of magnetic resonance angiography? J Neurol Neurosurg Psychiatry 2001;71:155-160.

16. Ozaki CK, Irwin PB, Flynn TC Huber TS, Seeger JM. Surgical decision making for carotid endarterectomy and contemporary magnetic resonance angiography. Am J Surg 1999;178:182-184.

17. Johnston DCC, Goldstein LB. Clinical carotid endarterectomy decision making. Noninvasive vascular imaging versus angiography. Neurology 2001;56:1009-1015.

18. Larkin M. Should endarterectomy decisions be based on noninvasive imaging? Lancet 2001;357:1343.

19. Rothwell PM, Pendlebury ST, Wardlaw J, Warlow CP. Critical appraisal of the design and reporting of studies imaging and measurement of carotid stenosis. Stroke 2000;31:1444-1450.

20. Nederkoorn PJ, Mali WP, Eikelboom BC, et al. Preoperative diagnosis of carotid artery stenosis. Accuracy of noninvasive testing. Stroke 2002;33:2003-2008.

21. Chaturvedi S, Policherla PN, Femino L. Cerebral angiography practices at US teaching hospitals. Implications for carotid endarterectomy. Stroke 1997;28:1895-1897.

22. Ruehm SG, Goyen M, Barkhausen J, et al. Rapid magnetic resonance angiography for detection of atherosclerosis. Lancet 2001;357:1086-1091.

23. Phan T, Huston J, Bernstein MA, Riederer SJ, Brown RD Jr. Contrast-enhanced magnetic resonance angiography of the cervical vessels. Experience with 422 patients. Stroke 2001;32:2282-2286.

24. Wutke R, Lang W, Fellner C, et al. High-resolution, contrastenhanced magnetic resonance angiography with elliptical centric $\mathrm{k}$-space ordering of supra-aortic arteries compared with selective x-ray angiography. Stroke 2002;33:1522-1529.

25. Fox AJ. How to measure carotid stenosis. Radiology 1993;186:316-318.

26. North American Symptomatic Carotid Endarterectomy Trial Collaborators. Beneficial effect of carotid endarterectomy in symptomatic patients with high-grade carotid stenosis. N Engl J Med 1991;325:445-453.

27. Barnett HJM, Taylor DW, Eliaziw M, et al, for the North American Symptomatic Carotid Endarterectomy Trial Collaborators. Benefit of carotid endarterectomy in patients with symptomatic moderate or severe stenosis. N Engl J Med 1998;339:1415-1425.

28. European Carotid Surgery Trialists' Collaborative Group. MRC European Carotid Surgery Trial: interim results for symptomatic patients with severe (70-99\%) or with mild $(0-29 \%)$ carotid stenosis. Lancet 1991;337:1235-1243.

29. European Carotid Surgery Trial. Endarterectomy for moderate symptomatic carotid stenosis: interim results from the MRC European Carotid Surgery Trial. Lancet 1996;347:1591-1593.

30. Mayberg MR, Wilson SE, Yatsu F, et al, for the Veterans Affairs Cooperative Studies Program 309 Trialist Group. Carotid endarterectomy and prevention of cerebral ischemia in symptomatic carotid stenosis. JAMA1993;266:3289-3294.

31. Hobson RW, Weiss DG, Fields WS, et al, for the Veterans Affairs Cooperative Study Group. Efficacy of carotid endarterectomy for asymptomatic carotid stenosis. N Engl J Med 1993;328:221-227.

32. Executive Committee for the Asymptomatic Carotid Atherosclerosis Study. Endarterectomy for asymptomatic carotid artery stenosis. JAMA1995;273:1421-1428.

33. Rothwell PM, Eliasziw M, Gutnikow A, et al; Carotid Endarterectomy Trialists'Collaboration. Analysis of pooled data from the randomized controlled trials of endarterectomy for symptomatic carotid stenosis. Lancet 2003;361:107-116.

34. Barnett HJM, Meldrum HE, Eliasziw M, for the North American Symptomatic Carotid Endarterectomy Trial (NASCET) Collaborators. The appropriate use of carotid endarterectomy. CMAJ 2002;166(9):1169-1179.
35. Kistler JP, Furie KL. Carotid endarterectomy revisited. N Engl J Med 2000;342:1693-1700.

36. Biller J, Feinberg WM, Castaldo JE, et al. Guidelines for carotid endarterectomy: a statement for healthcare professionals from a special writing group of the Stroke Council, American Heart Association. Stroke 1998;29:554-562.

37. Gorelick PB, Sacco RL, Smith DB, et al. Prevention of a first stroke: a review of guidelines and a multidisciplinary consensus statement from the National Stroke Association. JAMA 1999;281:1112-1120.

38. Sacco RL. Clinical Practice. Extracranial carotid stenosis. New Engl J Med 2001;345(15):1113-1118.

39. Perry JR, Szalai JP, Norris JW, for the Canadian Stroke Consortium. Consensus against both endarterectomy and routine screening for asymptomatic carotid stenosis. Arch Neurol 1997; 54:25-28.

40. Barnett HJ, Meldrum ME. Carotid endarterectomy: a neurotherapeutic advance. Arch Neurol 2000;57:40-45.

41. Moore WS, Barnett JHM, Beebe HG, et al. Guidelines for carotid endarterectomy: a multidisciplinary consensus statement from the Ad Hoc Committee, American Heart Association. Stroke 1995;26:188-201.

42. Findlay JM, Tucker WS, Ferguson GG, et al. Guidelines for the use of carotid endarterectomy: current recommendations from the Canadian Neurosurgical Society. Can Med Assoc J 1997;157(6):653-659.

43. Wolf PA, Clagett GP, Easton JD, et al. Preventing ischemic stroke in patients with prior stroke and transient ischemic attack: a statement from healthcare professionals from the Stroke Council of the American Heart Association. Stroke 1999;30:1991-1994.

44. Albers GW, Hart RG, Lutsep HL, Newell DW, Sacco RL. Supplement to the guidelines for the management of transient ischemic attacks: a statement from the Ad Hoc Committee on Guidelines for the Management of Transient Ischemic Attacks, Stroke Council, American Heart Association. Stroke 1999;30:2502-2511.

45. Benavente O, Eliasziw M, Streifler JY, et al; North American Symptomatic Carotid Endarterectomy Trial Collaborators. Prognosis after transient monocular blindness associated with carotid artery stenosis. N Engl J Med 2001;345(15):1084-1090.

46. Morgenstern LB, Fox AJ, Sharpe BL, et al. The risks and benefits of carotid endarterectomy in patients with near occlusion of the carotid artery. Neurology 1997;48:911-915.

47. Rothwell PM, Gibson R, Warlow CP, on behalf of the European Carotid Trialists' Collaborative Group. Interrelation between plaque surface morphology and degree of stenosis on carotid angiograms and the risk of ischemic stroke in patients with symptomatic carotid stenosis. Stroke 2000;31:615-621.

48. Eliasziw M, Streifler JY, Fox AJ, et al. Significance of plaque ulceration in symptomatic patients with high-grade carotid stenosis. Stroke 1994;25:304-308.

49. Gasecki AP, Eliasziw M, Ferguson GG, Hachinski V, Barnett HJ. Long-term prognosis and effect of endarterectomy in patients with symptomatic severe carotid stenosis and contralateral carotid stenosis or occlusion: results from NASCET. J Neurosurg 1995;83:778-782

50. Villarreal J, Silva J, Eliasziw M, et al for the North American Symptomatic Carotid Endarterectomy Trial (NASCET) Group. Prognosis of patients with an intraluminal thrombus in the internal carotid artery. Stroke 1998;29:276.

51. Kappelle LJ, Eliasziw M, Fox AJ, Sharpe BL, Barnett HJ. Importance of intracranial atherosclerotic disease in patients with symptomatic stenosis of the internal carotid artery. Stroke 1999;30:282-286.

52. Henderson RD, Eliasziw M, Fox AJ, Rothwell PM, Barnett HJ. Angiographically defined collateral circulation and risk of stroke in patients with severe carotid artery stenosis. Stroke 2000;31:128-132.

53. Streifler JY, Eliasziw M, Benavente OR, et al, North American Symptomatic Carotid Endarterectomy Trial Group. Prognostic importance of leukoaraiosis in patients with symptomatic internal carotid artery stenosis. Stroke 2003;33:1651-1655. 
54. The European Carotid Surgery Trialists Collaborative Group. Risk of stroke in the distribution of an asymptomatic carotid artery. Lancet 1995;345:209-212.

55. Inzitari D, Eliasziw M, Gates $P$, et al. The causes and risk of stroke in patients with asymptomatic internal-carotid artery stenosis. $\mathrm{N}$ Engl J Med 2000;342:1693-1700.

56. Hougaku H, Matsumoto M, Handa N, et al. Asymptomatic carotid lesions and silent cerebral infarction. Stroke 1994;25:566-570.

57. Norris JW, Zhu CZ, Bornstein NM, Chambers BR. Vascular risks of asymptomatic carotid stenosis. Stroke 1992;22:1485-1490.

58. Moore WS, Boren C, Malone JM, et al. Natural history of nonstenotic, asymptomatic ulcerative lesions of the carotid artery. Arch Surg 1978;113:1352-1359.

59. Dixon S, Pais SO, Raivola C, et al. Natural history of nonstenotic, asymptomatic ulcerative lesions of the carotid artery: a further analysis. Arch Surg 1982;117:1493-1498.

60. Autret A, Pourcelot L, Saudea D, et al. Stroke risk in patients with carotid stenosis. Lancet 1987;1:888-890.

61. Weschler LR. Ulceration and carotid artery disease. Stroke 1988; 19:650-653.

62. Rutgers DR, Klijn CJM, Kappelle LJ, et al. Sustained bilateral hemodynamic benefit of contralateral carotid endarterectomy in patients with symptomatic internal carotid artery occlusion. Stroke 2001;32:728-734.

63. Liapis CD, Kakisis JD, Kostakis AG. Carotid stenosis. Factors affecting symptomatology. Stroke 2001;32:2782-2786.

64. Golledge J, Greenhalgh RM, Davies AH. The symptomatic carotid plaque. Stroke 2000;31:774-781.

65. Bock RW, Grey-Weale AC, Mock PA, et al. The natural history of asymptomatic carotid artery disease. J Vasc Surg 1993;17:160-171.

66. Reilly LM, Lusby RJ, Hughes L, et al. Carotid plaque histology using real-time ultrasonography. Clinical and therapeutic implications. Am J Surg 1983;146:188-193.

67. AbuRahma AF, Wulu JT, Crotty B. Carotid plaque ultrasonic heterogeneity and severity of stenosis. Stroke 2002;33:1772-1775.

68. Molloy J, Markus HS. Asymptomatic embolization predicts stroke and TIA risk for patients with carotid artery stenosis. Stroke 1999;30(7):1440-1443.

69. Kallikazaros I, Tsioufis C, Sideris S, Stefanadis C, Toutouzas P. Carotid artery disease as a marker for the presence of severe coronary artery disease in patients evaluated for chest pain. Stroke 1999;30:1002-1007.

70. Gerraty RP, Gates PC, Doyle JC. Carotid stenosis and perioperative stroke risk in symptomatic and asymptomatic patients undergoing vascular or coronary surgery. Stroke 1993;24:11151118.

71. Ricotta JJ, Faggioli GL, Castilone A, Hassett JM. Risk factors for stroke after cardiac surgery: Buffalo Cardiac-Cerebral Study Group. J Vasc Surg 1995; 21:359-363.

72. Palerme LP, Hill AB, Obrand D, Steinmetz OK. Is Canadian cardiac surgeons' management of asymptomatic carotid artery stenosis at coronary artery bypass supported by the literature? A survey and a critical appraisal of the literature. Can J Surg 2000;43:93-103.

73. Das SK, Brow TD, Pepper J. Continuing controversy in the management of concomitant coronary and carotid disease: an overview. Int J Cardiol 2000;74:47-65.

74. Takach TJ, Reul GJ Jr, Cooley DA, et al. Is an integrated approach warranted for concomitant carotid and coronary artery disease? Ann Thorac Surg 1997;64:16-22.

75. Darling RC III, Dylewski M, Chang BB, et al. Combined carotid endarterectomy and coronary artery bypass grafting does not increase the risk of perioperative stroke Cardiovasc Surg 1998;6:448-452.

76. Minami K, Fukahara K, Boethig D, et al. Long-term results of simultaneous carotid endarterectomy and myocardial revascularization with cardiopulmonary bypass used for both procedures. J Thorac Cardiovasc Surg 2000;19:764-773.

77. Estes JM, Khabbaz KR, Barnatan M, Carpino P, Mackey WC. Outcome after combined carotid endarterectomy and coronary artery bypass is related to patient selection. J Vasc Surg 2001;33:1179-1184.
78. Landesberg G, Wolf Y, Schechter D, et al. Preoperative thallium scanning, selective coronary revascularization, and long-term survival after carotid endarterectomy. Stroke 1998;29:2541-2548.

79. Lopes DK, Mericle RA, Lanzino G, et al. Stent placement for the treatment of occlusive atherosclerotic carotid artery disease in patients with concomitant coronary artery disease. J Neurosurg 2002;96:490-496.

80. Little JR, Moufarrij NA, Furlan AJ. Early carotid endarterectomy after cerebral infarction. Neurosurgery 1989;24:334-338.

81. Gasecki AP, Ferguson GC, Eliasziw M. Early endarterectomy for severe carotid artery stenosis after a nondisabling stroke: results from the North American Symptomatic Carotid Endarterectomy Trial. J Vasc Surg 1994;2:288.

82. Hoffman M, Robbs J. Carotid endarterectomy after recent cerebral infarction. Eur J Vasc Surg 1999;18(1):6-10.

83. Johnston SC, Gress DR, Browner WS, Sidney S. Short-term prognosis after emergency department diagnosis of TIA. JAMA 2000;284:2901-2906.

84. Blaser T, Hofmann K, Buerger T, et al. Risk of stroke, transient ischemic attack, and vessel occlusion before endarterectomy in patients with symptomatic severe carotid stenosis. Stroke 2002;33:1057-1062.

85. Findlay JM, Marchak BE. Reoperation for acute hemispheric stroke after carotid endarterectomy: is there any value? Neurosurgery 2002;50(3):486-492.

86. Henderson RD, Phan TG, Piepgras DG. Mechanisms of intracerebral hemorrhage after carotid endarterectomy. J Neurosurg 2001;5(6):964-969.

87. Zannetti S, Parente B, De Rango P, et al. Role of surgical techniques and operative findings in cranial and cervical nerve injuries during carotid endarterectomy. Eur J Vasc Endovasc Surg 1998;15(6):528-531.

88. Ferguson GG, Eliasziw M, Barr HW, et al. The North American Symptomatic Carotid Endarterectomy Trial: surgical results in 1415 patients. Stroke 1999;30(9):1751-1758.

89. Lanzino G, Couture D, Andreoli A, Guterman LR, Hopkins LN. Carotid endarterectomy: can we select surgical candidates at high risk for stroke and low risk for perioperative complications? Neurosurgery 2001;49(4):913-924.

90. Sundt TM Jr, Sandok BA, Wisnant JP. Carotid endarterectomy: complications and preoperative assessment of risk. Mayo Clin Proc 1975;50:301-306.

91. Sieber FE, Toung TJ, Diringer MN, Wang H, Long DM. Preoperative risks predict neurological outcome of carotid endarterectomy related stroke. Neurosurgery 1992;30(6):847854.

92. McCrory DC, Goldstein LB, Samsa GP, et al. Predicting complications of carotid endarterectomy. Stroke 1993;24(9):1285-1291.

93. Rothwell PM, Slattery J, Warlow CP. Clinical and angiographic predictors of stroke and death from carotid endarterectomy: systematic review. Br Med J 1997;315:1571-1577.

94. Goldstein LB, Samsa GP, Matchar DB, Oddone EZ. Multicenter review of preoperative risk factors for endarterectomy for asymptomatic carotid artery stenosis. Stroke 1998;29(4):750753.

95. Kucey DS, Bowyer B, Iron K, et al. Determinants of outcome after carotid endarterectomy. J Vasc Surg 1998;28(6):1051-1058.

96. Bond R, Narayan SK, Rothwell PM, Warlow CP. European Carotid Surgery Trialists'Collaborative Group. Clinical and radiographic risk factors for operative stroke death in the European Carotid Surgery Trial. Eur J Vasc Surg 2002; 23:108-116.

97. Rothwell PM, Slattery J, Warlow CP. A systematic comparison of the risks of stroke and death due to carotid endarterectomy for symptomatic and asymptomatic stenosis. Stroke 1996;27(2):266269.

98. Dardik A, Bowman HM, Gordon TA, Hsieh G, Perler BA. Impact of race on the outcome of carotid endarterectomy: a populationbased analysis of 9,842 recent elective procedures. Ann Sur 2000;232 (5):704-709.

99. Meyer FB, Piepgras DG, Fode NC. Surgical treatment of recurrent carotid artery stenosis. J Neurosurg 1994;80(5):781-787. 
100. AbuRahma AF, Jennings TG, Wulu JT, Tarakji L, Robinson PA. Redo carotid endarterectomy versus primary carotid endarterectomy. Stroke 2001;32:2787-2792.

101. Hill BB, Olcott C IV, Dalman RL, Harris EJ Jr, Zarins CK. Reoperation for carotid stenosis is as safe as primary carotid endarterectomy. J Vasc Surg 1999;30(1):26-35.

102. Johnson CA, Tollefson DFJ, Olsen SB, Andersen CA, McKeeJohnson J. The natural history of early recurrent carotid artery stenosis. Am J Surg 1999;177:433-436.

103. O'Neill L, Lanska DJ, Hartz A. Surgeon characteristics associated with mortality and morbidity following carotid endarterectomy. Neurology 2000;55:773-781.

104. Hannan EL, Popp AJ, Feustel P, et al. Association of surgical specialty and processes of care with patient outcomes for carotid endarterectomy. Stroke 2001;32:2890-2897.

105. Feasby TE. The appropriateness and effectiveness of stroke prevention. In: Hachinski V, Norris J. (Eds). Stroke Prevention. Oxford University Press, 2001: 295-312.

106. Segal HE, Rummel L, Wu B. The utility of PRO data on surgical volume: the example of carotid endarterectomy. Qual Rev Bull 1993;19:152-157.

107. Spetzler RF, Martin N, Hadley MN, et al. Microsurgical endarterectomy under barbiturate protection: a prospective study. J Neurosurg 1986;65:63-73.

108. Findlay JM, Lougheed W. Microsurgical endarterectomy. Tech Neurosurg 1977;3:34-44.

109. Shah DM, Darling RC III, Chang BB, Kreienberg PB, Paty PS. Carotid endarterectomy by eversion technique: its safety and durability. Ann Surg 1998;228:471-478.

110. Peiper C, Nowack J, Ktenidis K, et al. Eversion endarterectomy versus open thromboendarterectomy and patch plasty for the treatment of internal carotid artery stenosis. Eur J Vasc Endovasc Surg 2000;20:317-318.

111. Green RM, Greenberg R, Illig K, Shortell C, Ouriel K. Eversion endarterectomy of the carotid artery: technical considerations and recurrent stenoses. J Vasc Surg 2000;32:1052-1061.

112. Katras T, Baltazar U, Rush DS, et al. Durability of eversion carotid endarterectomy: comparison with primary closure and carotid patch angioplasty. J Vasc Surg 2001;34:453-458.

113. Cao P, Giordano G, De Rango P, et al. Eversion versus conventional carotid endarterectomy: late results of a prospective multicenter randomized trial. J Vasc Surg 2000;31:19-30.

114. Cao PG, de Rango P, Zannetti S, et al. Eversion versus conventional carotid endarterectomy for preventing stroke. Cochrane Database Syst Rev 1:CD001921, 2001.

115. Jackson MR, Clagett GP. Use of vein or synthetic patches in carotid endarterectomy. In: Loftus CM, Kresowik TK (Eds). Carotid Artery Surgery. New York: Thieme 1999:281-290.

116. Yamamoto Y, Piepgras DG, Marsh WR, Meyer FB. Complications resulting from saphenous vein patch graft after carotid endarterectomy. Neurosurgery 1996;39:670-675.

117. AbuRahma AF, Robinson PA, Saiedy S, Richmond BK, Khan J. Prospective randomized trial of bilateral carotid endarterectomies. Primary closure versus patching. Stroke 1999;30:1185-1189.

118. AbuRahma AF, Khan JH, Robinson PA, et al. Prospective randomized trial of carotid endarterectomy with primary closure and patch angioplasty with saphenous vein, jugular vein, and polytetrafluoroethylene: perioperative (30-day) results. J Vasc Surg 1996;24:998-1007.

119. Counsell CE, Salinas R, Naylor R, Warlow CP. A systematic review of the ramdomised trials of carotid patch angioplasty in carotid endarterectomy. Eur J Vasc Endovasc Surg 1997;13:345-354.

120. Hayes PD, Allroggen H, Steel S, et al. Randomized trial of vein versus Dacron patching during carotid endarterectomy: influence of patch type on postoperative embolization. J Vasc Surg 2001;3:994-1000.

121. O'Hara PJ, Hertzer NR, Mascha EJ, et al. A prospective, randomized study of saphenous vein patching versus synthetic patching during carotid endarterectomy. J Vasc Surg 2002;35:324-332.

122. Hugenholtz H, Elgie RG. Carotid thromboendarterectomy: a reappraisal. J Neurosurg 1980;53:776-783.

123. Meyer FB, Sundt TM, Piepgras DG, Sandok BA, Forbes G. Emergency carotid endarterectomy for patients with acute carotid occlusion and profound neurological deficits. Ann Surg 1986;203:82-89.

124. McCormick PW, Spetzler RF, Bailes JE, Zabramski JM, Frey JL. Thromboendarterectomy of the symptomatic occluded internal carotid artery. J Neurosurg 1992;76:752-758.

125. Kasper GC, Wladis AR, Lohr JM, et al. Carotid thromboendarterectomy for recent total occlusion of the internal carotid artery. J Vasc Surg 2001;33:242-249.

126. Cote R, Barnett HJM, Taylor DW. Internal carotid occlusion. A prospective study. Stroke 1983;14:898.

127. Lennard N, Smith JL, Gaunt ME, et al. A policy of quality control assessment helps to reduce the risk of intraoperative stroke during carotid endarterectomy. Eur J Vasc Surg 1999;17:234-240.

128. Zannetti S, Cao P, De Rango P, et al. Intraoperative assessment of technical perfection in carotid endarterectomy: a prospective analysis of 1305 completion procedures. Collaborators of the EVEREST study group. Eversion versus standard carotid endarterectomy. Eur J Vasc Surg 1999;18:52-58.

129. Padayachee TS, McGuinness CL, Modareski KB, Arnold JA, Taylor PR. Value of intraoperative duplex imaging during supervised carotid endarterectomy. Br J Surg 2001;88:389-392.

130. Panneton JM, Berger MW, Lewis BD, et al. Intraoperative duplex ultrasound during carotid endarterectomy. Vasc Surg 2001;35:1-9.

131. North American Symptomatic Carotid Endarterectomy Trial Collaborators. Surgical results in 1415 patients. Stroke 1999;30:1751-1758.

132. European Carotid Surgery Trial Collaborative Group. Variation in surgical and anesthetic technique and associations with operative risk in the European Carotid Surgery Trial: implications for trials of ancillary techniques. Eur J Vasc Endovasc Surg 2002;23:117126.

133. Knighton JD, Stoneham MD. Carotid endarterectomy. A survey of anaesthetic practice. Anaesthesia. 2000;55:475-488.

134. Cheng MA, Theard MA, Tempelhoff R. Anesthesia for carotid endarterectomy: a survey. J Neurosurg Anesthesiol 1997;9:211216.

135. Finocchi C, Gandolfo C, Tiziana C, Del Sette M, Bertoglio C. Role of transcranial Doppler and stump pressure during carotid endarterectomy. Stroke 1997;28:2448-2452.

136. Sundt TM, Sharbrough FW, Piepgras DG, et al. Correlation of cerebral blood flow and electroencephalographic changes during carotid endarterectomy. Mayo Clin Proc 1981;56:533-543.

137. Wellman BJ, Loftus CM, Kresowick TF, Todd M, Granner MA. The differences in electroencephalographic changes in patients undergoing carotid endarterectomies while under local versus general anesthesia. Neurosurgy 1998;43:769-773.

138. Manninen PH, Tan TK, Sarjeant RM. Somatosensory evoked potential monitoring during carotid endarterectomy in patients with a stroke. Anesth Analg 2001;93:39-44.

139. McCarthy RJ, McCabe AE, Walker R, Horrocks M. The value of transcranial doppler in predicting cerebral ischemia during carotid endarterectomy. Eur J Vasc Endovasc Surg 2001;21:408412.

140. Ackerstaff RGA, Moons KGM, van de Vlasakker CJW, et al. Association of intraoperative transcranial doppler variables with stroke from carotid endarterectomy. Stroke 2000;31:1817-1823.

141. Dalman JE, Beenakkers ICM, Moll FL, Leusink JA, Ackerstaff RGA. Transcranial doppler monitoring during carotid endarterectomy helps to identify patients at risk of postoperative hyperperfusion. Eur J Vasc Endovasc Surg 1999;18:222-227.

142. Beese U, Langer H, Lang W, Dinkel M. Comparison of near infrared spectroscopy and somatosensory evoked potentials for the detection of cerebral ischemia during carotid endarterectomy. Stroke 1998;2032-2037.

143. Samra SK, Dy EA, Welch K, et al. Evaluation of a cerebral oximeter as a monitor of cerebral ischemia during carotid endarterectomy. Anesthesiology 2000;93:964-970.

144. Pandit JJ, Bree S, Dillon P, et al. A comparison of superficial versus combined (superficial and deep) cervical plexus block for carotid 
endarterectomy: a prospective, randomized study. Anesth Analg 2000;91:781-786.

145. Bourke DL, Thomas P. Mandibular nerve block in addition to cervical plexus block for carotid endarterectomy. Anesth Analg 1998;87:1034-1036.

146. Tangkanakul C, Counsell C, Warlow C. Local versus general anesthesia for carotid endarterectomy (Cochrane Review). In: The Cochrane Library, Issue 2, 2002.

147. Taylor DW, Barnett HJ, Haynes RB, et al. Low-dose and high-dose acetylsalicylic acid for patients undergoing carotid endarterectomy: a randomised controlled trial: ASA and carotid endarterectomy (ACE) trial collaborators. Lancet 1999;353: 2179-2184.

148. Rigdon EE, Manajjem N, Rhodes RS. Criteria for selective utilization of the intensive care unit following carotid endarterectomy. Ann Vasc Surg 1997;11:220-237.

149. Harbaugh KS, Harbaugh RE. Early discharge after carotid endarterectomy. Neurosurgery 1995;37:219-225.

150. Radak D, Popovic AD, Radicevic S, Neskovic AN, Bojic M. Immediate reoperation for perioperative stroke after 2250 carotid endarterectomies: differences between intraoperative and early postoperative stroke. J Vasc Surg 1999;30:245-251.

151. Rockman CB, Castillo J, Adelman MA, et al. Carotid endarterectomy in female patients: are the concerns of the asymptomatic carotid atherosclerosis study valid? J Vasc Surg 2001;33:236-240.

152. Barr JD, Horowitz MB, Mathis JM, Sclabassi RJ, Yonas H. Intraoperative urokinase infusion for embolic stroke during carotid endarterectomy. Neurosurgery 1995;36:606-611.

153. Winkelaar GB, Salvian AJ, Fry PD, et al. Intraoperative intraarterial urokinase in early postoperative stroke following carotid endarterectomy: a useful adjunct. Ann Vasc Surg 1999; 13:566-570.

154. Perler BA, Murphy K, Sternbach Y, Gailloud P, Shake JG. Immediate postoperative thrombolytic therapy: an aggressive strategy for neurologic salvage when cerebral thromboembolism complicates carotid endarterectomy. J Vasc Surg 2000;31:10331037.

155. Anzuini A, Briguori C, Roubin GS, et al. Emergency stenting to treat neurological complications occurring after carotid endarterectomy. J Am Coll Cardiol 2001;15:2074-2079.

156. Yadav JS, Roubin GS, Iyer S, et al. Elective stenting of the extracranial carotid arteries. Circulation 1997;95:376-381.

157. Roubin GS, New G, Iyer SS, et al. Immediate and late clinical outcomes of carotid artery stenting in patients with symptomatic and asymptomatic carotid artery stenosis. Circulation 2001; 103:532-543.

158. Wholey MH, Wholey M, Mathias K, et al. Global experience in cervical artery stent placement. Catheter Cardiovasc Interv 2000;50:160-167.

159. Higashida R. Treatment of carotid occlusive disease. An update on CREST and the carotid stenting trials. Proc. Sixth Joint Meeting of the AANS/CNS Section on Cerebrovascular Surgery and the American Society of Interventional and Therapeutic Neuroradiology. Phoenix, Feb 2003:21.

160. Iyer SS, Roubin GS, Vitek JJ. Carotid stenting with neuroprotection. Circulation 2002;34:30a.

161. Whitlow PL, Lylyk P, Londero H, et al. Carotid endarterectomy stenting protected with an emboli containment system. Stroke 2002;33:1308-1314

162. Al-Mubarak N, Roubin GS, Vitek JJ, New G, Iyer SS. Procedural safety and short-term outcome of ambulatory carotid stenting. Stroke 2001;32:2305-2309.

163. Fox DJ Jr, Moran CJ, Cross DT3rd, et al. Long-term outcome after angioplasty for symptomatic extracranial carotid stenosis in poor surgical candidates. Stroke 2002;33:2877-2885.

164. Malek AM, Higashida RT, Phatouros CC, et al. Stent angioplasty for cervical carotid artery stenosis in high-risk symptomatic NASCET-ineligible patients. Stroke 2000;32:3029-3037.

165. Brott TG. Angioplasty and stenting should only be performed in the setting of a clinical trial. Stroke 2002;33:2519-2520.

166. Barnett HJM. Carotid angioplasty/stenting versus endarterectomy. J Clin Neuroscience 2001;8:591-593.

167. Barth A. Patient selection for carotid angioplasty and stenting. Stroke 2002;33:2347-2348.

168. Endovascular versus surgical treatment in patients with carotid stenosis in the Carotid and Vertebral Artery Transluminal Angioplasty Study (CAVATAS): a randomized trial. Lancet 2001;357:1729-1737.

169. Rothwell PM, Eliasziw M, Gutnikov SA, et al; Carotid Endarterectomy Trialists' Collaboration: analysis of pooled data from the randomized controlled trials of endarterectomy for symptomatic carotid stenosis. Lancet 2003;361:107-116.

170. Kilaru S, Korn P, Kasirajan K, et al. Is carotid angioplasty and stenting more cost effective than carotid endarterectomy? J Vasc Surg 2003;37:331-339.

171. Warren JA, Jordan WD, Heudebert GR, Whitley D, Wirthlin DJ. Determining patient preference for treatment of extracranial carotid artery stenosis: carotid angioplasty and stenting versus endarterectomy. Ann Vasc Surg 2003;17:15-21.

172. Stoneburner JM, Nishanian GP, Cukingnan RA, Carey JS. Carotid endarterectomy using regional anaesthesia: a benchmark for stenting. Am Surg 2002;68:1120-1123.

173. Roubin GS. Angioplasty and stenting should not be restricted to clinical trials. Stroke 2002;33:2520-2522.

174. Wholey MH, Jarmolowski CR, Wholey M, Eles GR. Carotid artery stent placement - ready for prime time? J Vasc Interv Radiol 2003;14:1-10.

175. Hobson RW, Brott TG, Ferguson R, et al. CREST. Carotid revascularization endarterectomy versus stent trial. Cardiovasc Surg 1997; 5:457-458.

176. Wells KB. Treatment research at the crossroads: the scientific interface of clinical trials and effectiveness research. Am J Psychiat 1999;156:5-10.

177. Feasby TE, Quan H, Ghali WA. Hospital and surgeon determinants of carotid endarterectomy outcomes. Arch Neurol 2002;59:18771881.

178. Wong J, Findlay JM, Suarez-Almazor M. Regional performance of carotid endarterectomy: appropriateness, outcomes and risk factors for complications. Stroke 1997;28:891-898.

179. Karp HR, Flanders WD, Shipp CC, Taylor B, Martin D. Carotid endarterectomy among Medicare beneficiaries: a statewide evaluation of appropriateness and outcome. Stroke 1998;29:46-52.

180. Mayo SW, Eldrup-Jorgensen J, Lucas FL, Wennberg DE, Bredenberg CE. Carotid endarterectomy after NASCET and ACAS: a statewide study. North American Symptomatic Carotid Endarterectomy Trial. Asymptomatic Carotid Artery Stenosis Study. J Vasc Surg 1998;27(6):1017-1022.

181. Cebul RD, Snow RJ, Pine R, Hertzer NR, Norris DG. Indications, outcomes, and provider volumes for carotid endarterectomy. JAMA1998;279(16):1282-1287.

182. Kresowick TF, Hemann RA, Grund SL, et al. Improving the outcomes of carotid endarterectomy: results of a statewide quality improvement project. J Vasc Surg 2000;31:918-926.

183. Oliver SE, Thomson RG. Are variations in the use of carotid endarterectomy explained by population need? A study of health service utilisation in two English health regions. Eur J Vasc Endovasc Surg 1999;17(6):501-506.

184. Ferris G, Roderick P, Smithies A, et al. An epidemiological needs assessment of carotid endarterectomy in an English health region. Is the need being met? Br Med J 1998;317:447-451.

185. Findlay JM, Nykolyn L, Lubkey TB, et al. Auditing carotid endarterectomy: a regional experience. Can J Neurol Sci 2002;29:326-332. 